\title{
Chapitre IX - Une phase de progression (1865-1920)
}

\section{Maurice Wolkowitsch}

\section{(2) OpenEdition}

\section{Journals}

Édition électronique

URL : https://journals.openedition.org/rhcf/1326

DOI : 10.4000/rhcf.1326

Éditeur

Rails \& histoire

\section{Édition imprimée}

Date de publication : 10 février 2004

Pagination : 282-337

ISBN : 0996-9403

ISSN : 0996-9403

\section{Référence électronique}

Maurice Wolkowitsch, "Chapitre IX - Une phase de progression (1865-1920)», Revue d'histoire des chemins de fer [En ligne], 30 | 2004, mis en ligne le 19 août 2012, consulté le 22 avril 2022. URL : http:// journals.openedition.org/rhcf/1326; DOI : https://doi.org/10.4000/rhcf.1326 


\section{Chapitre IX \\ Une phase de progression (1865-1920)}

T'évolution des réseaux de chemins de fer secondaires doit

L être examinée dans le temps et dans l'espace. Comme ils sont nés sous différents statuts, une analyse propre à chacun de ceux-ci est nécessaire; ils n'évoluent pas au même rythme. Une synthèse présentant l'évolution de l'ensemble des réseaux peut alors être offerte ; cet ensemble détermine les conditions de transport des personnes et des biens dans un cadre territorial donné, le département ; les services assurés par les lignes d'intérêt général doivent bien entendu être pris en compte.

Une première période est caractérisée par une progression continue du réseau des CFIL et TVM ; elle s'étend de 1865 à 1913. Quelques compléments prévus avant guerre seront réalisés après la fin du conflit.

Un état des réseaux en 1911 peut être dressé en s'appuyant sur une cartographie qui intègre les résultats du recensement pour apprécier la densité du réseau pour $100 \mathrm{~km}^{2}$ et les kilomètres exploités pour 100000 habitants ; des cartes de la longueur des réseaux, de leur densité par unité de surface apportent des éclairages intéressants ${ }^{1}$.

La deuxième période est celle d'un inexorable déclin de l'exploitation par voie ferrée dont l'héritage au XxI ${ }^{\mathrm{e}}$ siècle est plus que limité. La concurrence automobile des années 1920 et la crise économique des années 1930 conduisent à une baisse du trafic multipliant les exploitations déficitaires et l'ampleur des déficits. Malgré une lutte pour la survie à travers la diversification des techniques, les cessations d'activités sont fréquentes. Cependant toutes les entreprises ne disparaissent pas, certaines opèrent avec succès leur reconversion.

\section{La progression des réseaux}

. Réseaux de CFIL et TVM

\section{$>$ L'évolution propre à chaque réseau}

\section{Le réseau né de la loi de 1865 (CFIL) (Fig. 4)}

La loi de 1865 favorise la naissance du premier réseau de CFIL. Le nombre des concessions, le kilométrage à construire ou en construction, les mises en exploitation progressent à un rythme favorable, à peine troublé par la guerre de 1870 (tabl. 54). 1878 marque un renversement de tendance.

1- Les données sont bien entendu inexistantes pour l'Alsace et la Lorraine annexées, laissées en blanc. 


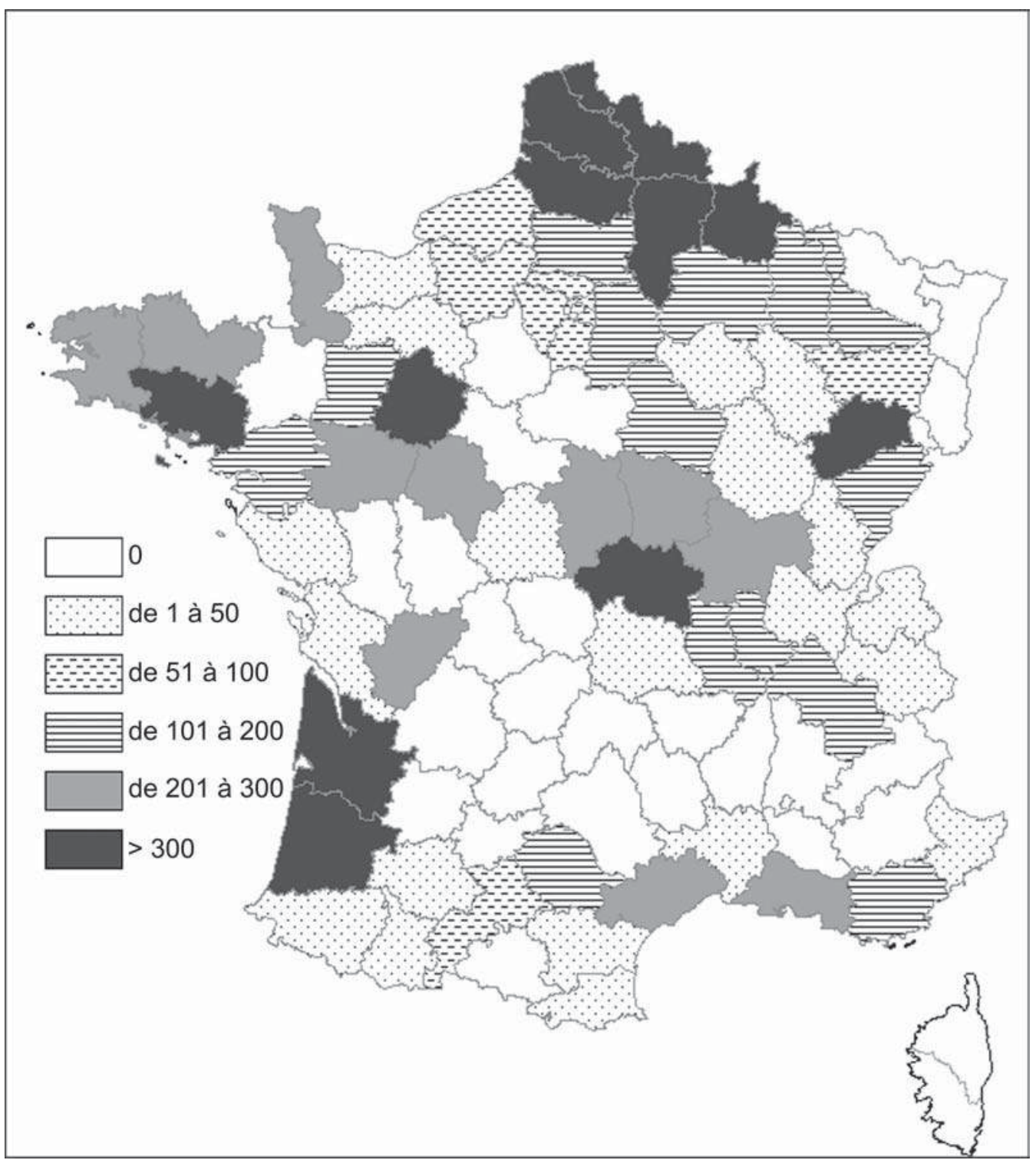

Figure 4. Longueur exploitée des chemins de fer d'intérêt local (lois de 1865 et de 1880) au 31/12/1911 (km, par département). @ M. Wolkowitsch / E. Auphan (UMR CNRS PRODIG), mai 1999 - Fond de carte InterCarto. 
Tableau 54. Évolution du réseau de CFIL (1865) en km, 1866-1877

\begin{tabular}{|c|c|c|c|c|c|}
\hline Années & $\begin{array}{c}\text { Lignes } \\
\text { à construire } \\
\text { ou en } \\
\text { construction }\end{array}$ & $\begin{array}{c}\text { Lignes } \\
\text { en } \\
\text { exploitation }\end{array}$ & Années & $\begin{array}{c}\text { Lignes } \\
\text { à construire } \\
\text { ou en } \\
\text { construction }\end{array}$ & $\begin{array}{c}\text { Lignes } \\
\text { en } \\
\text { exploitation }\end{array}$ \\
\hline $\mathbf{1 8 6 6}$ & 232 & 0 & $\mathbf{1 8 7 9}$ & 1713 & 2159 \\
\hline $\mathbf{1 8 6 9}$ & 1390 & 17 & $\mathbf{1 8 8 3}$ & 318 & 1427 \\
\hline $\mathbf{1 8 7 0}$ & 1521 & 293 & $\mathbf{1 8 9 0}$ & 228 & 1420 \\
\hline $\mathbf{1 8 7 1}$ & 1539 & 425 & $\mathbf{1 8 9 5}$ & 40 & 1107 \\
\hline $\mathbf{1 8 7 3}$ & 2350 & 1281 & $\mathbf{1 9 0 0}$ & 9 & 1057 \\
\hline $\mathbf{1 8 7 7}$ & 2827 & 2309 & $\mathbf{1 9 1 1}$ & 0 & 1011 \\
\hline
\end{tabular}

Les conseils généraux inquiets des faillites et abandons sont moins enclins à octroyer de nouvelles concessions. L'attentisme est aussi encouragé par les discussions en cours du plan Freycinet et des projets d'une nouvelle loi sur les CFIL ; mieux valait connaitre le régime des chemins de fer défini par ces futurs textes. En 1877, le réseau concédé, long de $5136 \mathrm{~km}$, était pour $45 \%$ en exploitation. Les lignes de ce réseau connaissent des sorts divers : abandonnées, exploitées sous le régime de la loi de 1880, ou incorporées aux réseaux d’intérêt général pour $3686 \mathrm{~km}$ dont 1000 au titre du plan Freycinet; en 1871, $200 \mathrm{~km}$ étaient cédés à l'Allemagne. Le réseau est de $1011 \mathrm{~km}$ en 1911, et comprend 21 lignes à écartement normal (80\% du kilométrage), cinq à voie étroite $(20 \%)$; la longueur moyenne des lignes ou réseaux est respectivement de 39,8 et 43,8 km. Le choix de la voie étroite est exclu par les concessionnaires dont l'objectif, à terme, est l'intégration de leurs lignes aux réseaux d'intérêt général ; la première concession à voie étroite date de 1874, elle intéresse $22 \mathrm{~km}$ entre Gray et Gy ; en 1884 seulement $253 \mathrm{~km}$ à voie étroite sont en exploitation sur 647 concédés, soit 9,4 et $13 \%$ du total. Le funiculaire de Fourvière relève de la loi de 1865.

\section{Le réseau né de la loi de 1880 (CFIL)}

La loi de 1880 répond à une attente; elle redonne aux élus une confiance que le sort réservé à leurs projets par les spéculateurs avait entamée. Pendant six ans, le nombre des concessions augmente et se traduit dans le kilométrage des lignes à construire ou en construction ; après une décennie de déclin, le dynamisme est retrouvé : en 1909, plus de $3000 \mathrm{~km}$ sont à construire ou en construction (tabl. 55). 1896 est le point de départ du rapide développement des CFIL ; le réseau s'enrichit en moyenne annuelle de $220 \mathrm{~km}$ entre 1884 et 1897, de 400 entre 1898 et 1911. 
Tableau 55. Évolution du réseau de CFIL (1880) en km, 1881-1911

\begin{tabular}{|c|c|c|c|c|c|}
\hline Années & $\begin{array}{c}\text { Lignes } \\
\text { à construire } \\
\text { ou en } \\
\text { construction }\end{array}$ & $\begin{array}{c}\text { Lignes } \\
\text { en } \\
\text { exploitation }\end{array}$ & Années & $\begin{array}{c}\text { Lignes } \\
\text { à construire } \\
\text { ou en } \\
\text { construction }\end{array}$ & $\begin{array}{c}\text { Lignes } \\
\text { en } \\
\text { exploitation }\end{array}$ \\
\hline $\mathbf{1 8 8 1}$ & 297 & 0 & $\mathbf{1 8 9 3}$ & 577 & 2435 \\
\hline $\mathbf{1 8 8 2}$ & 675 & 0 & $\mathbf{1 8 9 6}$ & 1022 & 2943 \\
\hline $\mathbf{1 8 8 3}$ & 942 & 0 & $\mathbf{1 9 0 0}$ & 1934 & 3725 \\
\hline $\mathbf{1 8 8 4}$ & 890 & 160 & $\mathbf{1 9 0 5}$ & 1739 & 5815 \\
\hline $\mathbf{1 8 8 5}$ & 1466 & 318 & $\mathbf{1 9 0 8}$ & 2832 & 6992 \\
\hline $\mathbf{1 8 8 6}$ & 1493 & 458 & $\mathbf{1 9 1 0}$ & 2713 & 7946 \\
\hline $\mathbf{1 8 9 0}$ & 740 & 1701 & $\mathbf{1 9 1 1}$ & 2134 & 8606 \\
\hline
\end{tabular}

Ces phases s'expliquent, d'une part, par des facteurs liés aux fluctuations de l'économie favorables ou non à la mobilisation de capitaux privés et à l'octroi de subventions publiques indispensables à l'exécution des projets, d'autre part par des facteurs spécifiques.

Après la promulgation de la loi, les conseils généraux multiplient les concessions, puis vient le temps de la réflexion et de l'évolution des esprits. L'idée de créer des compagnies concurrentes des grands réseaux est abandonnée au profit de la volonté d'établir des réseaux départementaux cohérents ou de relier, par une ligne, des zones enclavées à une gare d'une grande compagnie. Le temps des Delahante et des Philippart est révolu. Les milieux d'affaires intéressés aux CFIL ne rêvent plus d'établir des relations lointaines mais épousent les visions des élus. De puissantes compagnies, on l'a vu, s'intéressent à ce secteur d'activité : la Compagnie générale des chemins de fer départementaux, la Compagnie générale des chemins de fer vicinaux, chacune exploitant en 1911 près de $700 \mathrm{~km}$, surtout la SGCFE avec ses $1700 \mathrm{~km}$ de lignes, présente dans dix-huit départements. L'assise financière de ces entreprises rassure les élus quant à leur capacité de conduire les travaux à leur terme ; leurs interlocuteurs ne sont plus des spéculateurs, mais des bâtisseurs, futurs exploitants. Des compagnies d'initiative départementale, bénéficiant d'appuis financiers extérieurs, sont nombreuses ; elles exploitent de 200 à $400 \mathrm{~km}$ et jouissent souvent d'un monopole (Ardennes, Côtes-du-Nord, Finistère... ). Les particuliers n'interviennent plus que pour de courtes liaisons, leur indépendance est souvent toute relative, l'aboutissement de leur projet étant conditionné par l'appui de plus puissants, y compris, comme dans le Nord, les grandes compagnies. 
Une autre révolution dans les esprits est la recherche d'une construction économique avec l'adoption fréquente de la voie métrique, comme nous l'avons vu au chapitre précédent. Il fallait, on l'a dit, l'abandon de l'objectif de l'intégration aux réseaux d'intérêt général pour arriver à cette conception moins onéreuse permettant de multiplier les projets ; cette possibilité avait été peu utilisée sous le régime de la loi de 1865. Au début du $\mathrm{xx}^{\mathrm{e}}$ siècle, des lignes initialement prévues à voie normale seront réalisées à voie étroite : Nice à Digne ${ }^{2}$ et Le Blanc à Argent ${ }^{3}$.

La comparaison des résultats d'exploitation au kilomètre sur un réseau à voie métrique et sur une ligne du plan Freycinet avec des profils en long comparables est significative ${ }^{4}$.

En 1911, $8606 \mathrm{~km}$ sont exploités sous le régime de la loi de 1880. 28 lignes conçues à écartement normal ne représentent que $15 \%$ du kilométrage total de ce réseau ; leur longueur moyenne de $43 \mathrm{~km}$ montre la prédominance de concessions portant sur quelques dizaines de kilomètres. 66 concessions portent sur des itinéraires à voie métrique, elles occupent $85 \%$ du réseau ; la longueur moyenne de $110 \mathrm{~km}$ montre l'existence, à côté de courtes liaisons, des réseaux départementaux et des grandes sociétés de CFIL. Sept funiculaires $(3,2 \mathrm{~km})$, six chemins de fer à crémaillère, et les deux sociétés de métro parisien ${ }^{5}$ relèvent de ce régime d'exploitation.

2- Le conseil général des Alpes-Maritimes, sitôt formé en 1861, demande la construction d'une ligne de Nice à la vallée de la Durance ; les reliefs à vaincre font ajourner le projet. La défaite de 1870 conduit l'état-major à demander la construction rapide et à voie normale de cette liaison protégée d'une attaque par mer, menace sur la ligne longeant le littoral de l'Estérel. La concession accordée à Sud-France en 1888 prévoit l'emploi de la voie métrique, l'état-major s'étant désintéressé de cette liaison. La mise en service a lieu en 1911.

3- Un projet de 1868 prévoyait une construction à voie normale. L'Ouest et le PO refusaient la concession de cette ligne, souhaitée par l'état-major qui y voyait en revanche un itinéraire permettant depuis le Sud-Ouest de gagner l'Est par une rocade de lignes stratégiques évitant la région parisienne. Le rôle militaire de la future ligne oublié, une concession à voie métrique est accordée en 1893 au PO pour unir Le Blanc à Argent ; cette compagnie d'intérêt général sous-traite avec Faugère et Chatelin la construction et l'exploitation de cette relation pour le compte du PO. Les constructeurs créent la Société anonyme de la compagnie de chemin de fer du Blanc à Argent (octobre 1902). La mise en service a lieu par sections : Romorantin-Salbris 31 décembre 1901, Salbris-Argent 15 mai 1902, Romorantin-Écueillé 6 novembre 1902, Écueillé-Le Blanc 15 novembre 1902. En 1927, la ligne est exploitée par la Compagnie des tramways de l'Indre.

4- M. Wolkowitsch, «Le redéploiement des chemins de fer dans le département de l'Indre ", Rerue d'bistoire des chemins de fer, $\mathrm{n}^{\circ} 9$ (automne 1993), p. 144-162.

5- En 1911, la Compagnie des chemins de fer métropolitains de Paris $(75 \mathrm{~km}$ concédés, 4 exploités) et la Compagnie du chemin de fer souterrain Nord-Sud (12 km concédés, 4 exploités). 


\section{Le réseau né de la loi de 1880 (TVM) (fig. 5)}

Le réseau des TVM se développe plus lentement que celui des CFIL ; cinq ans après la promulgation de la loi de 1880, les kilométrages à construire ou en construction sont respectivement de 77 et 1466 . Le rythme s'élève et offre deux périodes de grand essor (1893-1900 et 1906-1910). La moyenne annuelle du kilométrage mis en exploitation passe de 126 entre 1884 et 1897 à 320 entre 1897 et 1911 : le réseau double de longueur dans la première décennie du $\mathrm{xx}^{\mathrm{e}}$ siècle (tabl. 56).

Tableau 56. Évolution du réseau de TVM (km)

\begin{tabular}{|c|c|c|c|c|c|c|c|}
\hline \multicolumn{3}{|c|}{$\begin{array}{c}\text { Lignes à construire et } \\
\text { en construction }\end{array}$} & \multicolumn{4}{c|}{ Lignes en exploitation } \\
\hline $\mathbf{1 8 8 1}$ & $59 \mathrm{~km}$ & $\mathbf{1 8 9 8}$ & $1532 \mathrm{~km}$ & $\mathbf{1 8 8 1}$ & $35 \mathrm{~km}$ & $\mathbf{1 8 9 7}$ & $1917 \mathrm{~km}$ \\
\hline $\mathbf{1 8 8 5}$ & $77 \mathrm{~km}$ & $\mathbf{1 9 0 0}$ & $1920 \mathrm{~km}$ & $\mathbf{1 8 8 4}$ & $142 \mathrm{~km}$ & $\mathbf{1 9 0 1}$ & $3292 \mathrm{~km}$ \\
\hline $\mathbf{1 8 8 6}$ & $325 \mathrm{~km}$ & $\mathbf{1 9 0 3}$ & $1335 \mathrm{~km}$ & $\mathbf{1 8 8 7}$ & $195 \mathrm{~km}$ & $\mathbf{1 9 0 2}$ & $3696 \mathrm{~km}$ \\
\hline $\mathbf{1 8 9 2}$ & $478 \mathrm{~km}$ & $\mathbf{1 9 0 6}$ & $2159 \mathrm{~km}$ & $\mathbf{1 8 8 8}$ & $364 \mathrm{~km}$ & $\mathbf{1 9 0 3}$ & $4051 \mathrm{~km}$ \\
\hline $\mathbf{1 8 9 3}$ & $929 \mathrm{~km}$ & $\mathbf{1 9 1 0}$ & $3007 \mathrm{~km}$ & $\mathbf{1 8 9 0}$ & $424 \mathrm{~km}$ & $\mathbf{1 9 0 4}$ & $4500 \mathrm{~km}$ \\
\hline $\mathbf{1 8 9 7}$ & $1168 \mathrm{~km}$ & $\mathbf{1 9 1 1}$ & $2816 \mathrm{~km}$ & $\mathbf{1 8 9 1}$ & $677 \mathrm{~km}$ & $\mathbf{1 9 0 6}$ & $5121 \mathrm{~km}$ \\
\hline & & & $\mathbf{1 8 9 4}$ & $1070 \mathrm{~km}$ & $\mathbf{1 9 0 9}$ & $6037 \mathrm{~km}$ \\
\cline { 5 - 8 } & & $\mathbf{1 8 9 5}$ & $1325 \mathrm{~km}$ & $\mathbf{1 9 1 1}$ & $6688 \mathrm{~km}$ \\
\hline
\end{tabular}

Les phases de l'évolution des réseaux de TVM dépendent des facteurs déjà évoqués à propos des CFIL, mais des facteurs spécifiques sont à prendre en compte. Concédants et concessionnaires ont besoin d'assimiler les articles de la loi instituant un troisième type de chemin de fer : le TVM. Son originalité est de faire du domaine public à travers les rues et les routes l'assiette de la voie. Quelles sont les conditions juridiques de l'utilisation du domaine public ? Concrètement, comment le tramway s'insérera-t-il parmi les usagers traditionnels de la route ? Les économies réalisées sur la construction d'une ligne seront-elles suffisantes pour compenser la réduction des subventions publiques prévues par rapport à celles obtenues pour construire un CFIL ? La banalisation de la voie métrique a été un facteur favorable en réduisant l'emprise du chemin de fer sur la route, assurant aux piétons et voitures à chevaux davantage de place et de sécurité. Dominant les problèmes, les élus concèdent alors de multiples lignes : le choix entre CFIL et TVM ne pourrait être expliqué qu'à travers l'analyse d'une multitude d'exemples pour lesquels des débats se seraient instaurés. 


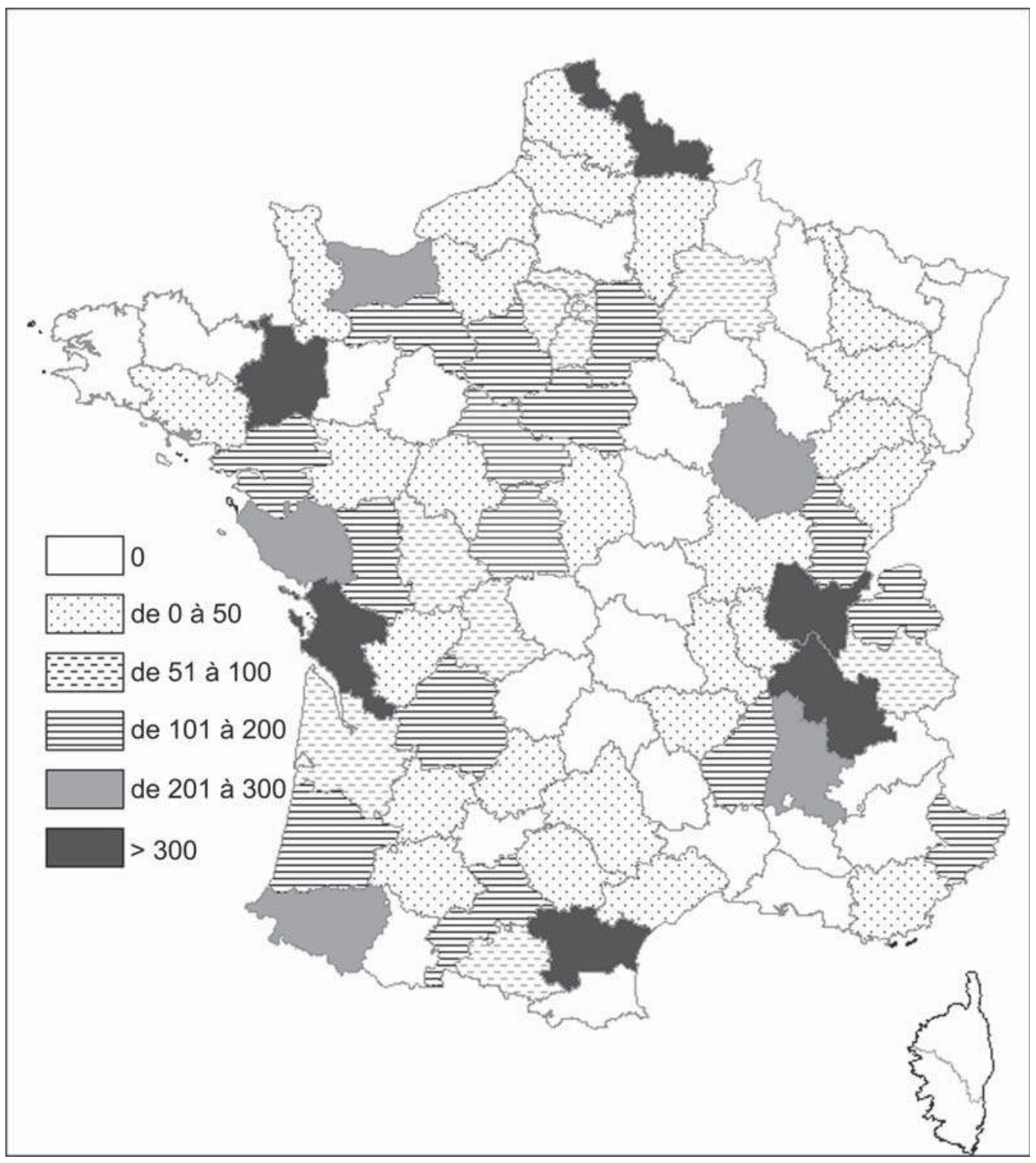

Figure 5. Longueur exploitée des tramways voyageurs et marchandises au 31/12/1911 (km, par département). (C) M. Wolkowitsch / E. Auphan (UMR CNRS PRODIG), mai 1999 - Fond de carte InterCarto. 
En 1911, les TVM parcourent un réseau de $6688 \mathrm{~km}$; les voies étroites dominent : la voie métrique sur $93 \%$ du kilométrage, l'écartement de 0,60 sur $5,3 \%$, soit $354 \mathrm{~km}$; avec $1,7 \%$ et $113 \mathrm{~km}$, la voie normale joue un rôle mineur. À l'image des CFIL, les TVM sont exploités par des entreprises de tous calibres ; le kilométrage moyen (66 km) pour les 100 concessionnaires concernés traduit cette situation. Les grands groupes, tels que la SGCFE, n'excluent pas d'intégrer dans leur réseau des lignes de TVM. Des particuliers exploitent des liaisons de moins de $10 \mathrm{~km}$ (Cassel, Rodez...). Des concessions départementales portant sur 100 à $400 \mathrm{~km}$ sont aussi en service (Aude, Ille-et-Vilaine), jouissant parfois d'un monopole (Haute-Vienne ou, à 98 \%, le réseau des Alpes-Maritimes).

L'analyse des réseaux montre comment les entreprises ont utilisé les possibilités offertes par les lois. Cette approche est insuffisante, puisque de nombreuses entreprises exploitent des lignes relevant de statuts différents $^{6}$. À cet argument juridique s'en ajoute un autre : c'est l'ensemble des lignes inscrites dans un territoire qui définit la qualité de la desserte. Une vue globale des réseaux de CFIL et de TVM s'impose.

\section{$>$ L'évolution de l'ensemble des réseaux secondaires (CFIL et TVM)}

Le kilométrage des lignes à construire ou en construction correspond au bilan entre la longueur des nouvelles concessions accordées dans l'année et celle des lignes mises en service. Nous retrouvons les phases signalées à propos des trois réseaux : hésitations entre 1875 et 1890, essor à la fin du XIx ${ }^{\mathrm{e}}$ siècle et au début du $\mathrm{Xx}^{\mathrm{e}}$; le mouvement se ralentit à partir de 1911. Près de 300 concessions ont été accordées tous régimes juridiques confondus; les unes portent sur une ligne, les autres sur plusieurs lignes ou sur un réseau. Il n'y a pas de concordance entre le nombre des concessions et celui des entreprises.

Tableau 57. Longueur totale des réseaux de chemins de fer secondaires (CFIL et TVM), 1870-1912 (en km)

\begin{tabular}{|c|c|c|c|c|c|}
\hline & $\begin{array}{c}\text { En construction } \\
\text { ou à construire }\end{array}$ & $\begin{array}{c}\text { En } \\
\text { exploitation }\end{array}$ & & $\begin{array}{c}\text { En construction } \\
\text { ou à construire } \\
\text { exploitation }\end{array}$ & $\begin{array}{c}\text { En } \\
\text { ex }\end{array}$ \\
\hline $\mathbf{1 8 7 0}$ & 1521 & 293 & $\mathbf{1 8 9 5}$ & 1779 & 5214 \\
\hline $\mathbf{1 8 7 5}$ & 2568 & 1798 & $\mathbf{1 9 0 0}$ & 3863 & 7612 \\
\hline $\mathbf{1 8 8 0}$ & 1586 & 2187 & $\mathbf{1 9 0 5}$ & 3365 & 11689 \\
\hline $\mathbf{1 8 8 5}$ & 1839 & 1910 & $\mathbf{1 9 1 0}$ & 5720 & 15347 \\
\hline $\mathbf{1 8 9 0}$ & 1355 & 3545 & $\mathbf{1 9 1 2}$ & 4950 & 16005 \\
\hline
\end{tabular}

6- Cf. ci-dessus p. 12, chapitre IV. 
La longueur du réseau exploité (tableau 57) croît sans cesse sauf lors du transfert de lignes de CFIL (1865) au réseau d'intérêt général (1881-1885). Le réseau des chemins de fer secondaires triple entre 1895 et 1910, desservant les espaces délaissés par les lignes du plan Freycinet.

En 1911, les réseaux secondaires se densifient sur le territoire national ; $4950 \mathrm{~km}$ sont encore en construction ou à construire, 4565 en 1913. Les nouvelles concessions portent sur de courtes liaisons, prolongements d'une ligne ou compléments au sein d'un réseau ; en 1911, $83 \mathrm{~km}$ pour trois concessionnaires de CFIL, $77 \mathrm{~km}$ pour neuf de TVM. Le kilométrage annuellement concédé n'équilibre plus celui des mises en service. Le réseau continue cependant de progresser. 1911: $16305 \mathrm{~km}$; 1913 : 18526 ; 1927 : 20 249. Il atteint alors son maximum d'extension. Des projets retardés par la guerre n'ont abouti qu'au début des années vingt : dix départements s'enrichissent de plus de $80 \mathrm{~km}$ de nouvelles liaisons ${ }^{7}$. Le retour des provinces perdues apporte $212 \mathrm{~km}$, mais des lignes détruites pendant les opérations militaires dans le Nord ne seront pas reconstruites ${ }^{8}$.

\section{. Les réseaux de TV et de TVB}

Le développement des lignes à construire ou en construction est lent : quelques kilomètres par an entre 1855 et 1872 ; les projets se multiplient à partir de 1896 et le mouvement se poursuit au début du $\mathrm{xx}^{\mathrm{e}}$ siècle. On construit en moyenne sept kilomètres par an entre 1855 et 1874, 37 entre 1875 et 1894, 85 entre 1895 et 1911. Sans doute les progrès de l'électrification favorisent-ils la réalisation de réseaux urbains à un moment où la croissance de certaines villes en justifie la construction.

La première ligne de tramways est exploitée sur $15 \mathrm{~km}$ en 1855 , douze ans avant la première ligne de CFIL et 26 avant celle de TVM. Le réseau ne compte encore que $82 \mathrm{~km}$ en 1875, 1076 en 1898 et atteint 3172 en $1911 ; 54 \%$ du réseau est à écartement normal. Le réseau de TV se divise en deux entités distinctes, les tramways pour voyageurs et ceux pour voyageurs, bagages et messageries ; avec $929 \mathrm{~km}$, ces derniers représentent $29 \%$ de la totalité du réseau de TV.

Une première ligne est concédée en 1853 dans Paris pour unir Vincennes à Sèvres et Saint-Cloud. La technique ramenée des ÉtatsUnis par Loubat, qui l'a vue expérimenter à New-York, est celle de la

7- Longueur des lignes en $\mathrm{km}$ : Sarthe : 146 ; Vienne : 139; Tarn-et-Garonne : 124 ; Meuse : 117 ; Oise : 100 ; Yonne : 98 ; Lot-et-Garonne : 95 ; Alpes-Maritimes : 87; Morbihan: 86 ; Vendée : 80.

8- Voir Sandrine Legrand, «La reconstruction des voies ferrées d'intérêt local dans le Pas-de-Calais après la Première Guerre mondiale », mémoire de maitrise d'histoire, université d'Artois, 1998. 
voiture sur rail, tirée par des chevaux, le tramway dit chemin de fer américain. Le refus de l'administration de poser des rails sur les ChampsÉlysées devait imposer pendant près de 20 ans de limiter la ligne au parcours urbain et, surtout, qu'on soulève au coin des Champs-Elysées les voitures sur des crics pour passer des roues à boudin aux roues ordinaires et vice-versa $a^{9}$. Le réseau hippomobile se développe à partir de $1875: 300 \mathrm{~km}$ sont progressivement mis en service en 25 ans. La Compagnie générale des omnibus de Paris qui monopolise presque tous les services intra-muros voit des sociétés concurrentes, Tramways du Nord, Tramways du Sud exploiter des lignes suburbaines; les faillites sont fréquentes, mais d'autres sociétés naissent.

À l'étranger et dans de multiples villes de province (Marseille, Lyon, Clermont-Ferrand, Le Havre, Rouen, Angers, Dijon), des tramways à vapeur plus rapides étaient en service. Sous la pression de la clientèle, les compagnies parisiennes sont conduites à partir de 1889 à se convertir à l'emploi de moteurs mécaniques avec appel aux techniques les plus variées : la vitesse des véhicules conduit à un arrêté préfectoral imposant aux autres voitures de leur laisser la priorité. Dès 1890, un tramway électrique est en service à Clermont-Ferrand, suivi par de multiples villes, dont Paris en 1898. En 1900, cette technique a conquis plusieurs dizaines de villes.

Les lignes se multipliant, dans les grandes villes les compagnies se font plus nombreuses. Les réseaux sont imbriqués les uns dans les autres ; les emprunts d'itinéraires entre compagnies deviennent fréquents. On comprend l'avis figurant dans le document du ministère des Travaux publics : «pendant la période de transformation de divers réseaux de tramways dans le département de la Seine, et en attendant l'application de nouveaux modes de traction prévus aux cahiers des charges, certaines lignes suivront provisoirement un itinéraire différent de celui indiqué ci-dessous ${ }^{10}$. » La longueur exploitée ou à exploiter cesse d'être obligatoirement conforme à la concession originelle, la recherche d'une rationalisation de l'utilisation des infrastructures entrainant l'emprunt de nouveaux itinéraires.

Cette progression généralisée des chemins de fer secondaires nous engage, après deux décennies de développement spectaculaire à en dresser le bilan. Nous sommes en 1911.

9- G. d’Avenal, « Le mécanisme de la vie moderne : les moyens de transports urbains : tramways, bateaux, métropolitains », Revue des Deux-Mondes, 10 avril 1903, p. 583-609. 10- La liste des nouveaux itinéraires avec leur longueur par sections figure en dessous des tableaux inventoriant les lignes de chaque concession dans l'inventaire du ministère des Travaux publics. 


\section{La situation des réseaux des chemins de fer secondaires en 1911}

Le trafic des réseaux secondaires permet l'optimisme. Les entreprises offrent pour beaucoup d'entre elles des coefficients d'exploitation satisfaisants. L'avenir se concrétise dans des projets de compléter les réseaux à travers les campagnes et les nouveaux quartiers urbains. Ces chemins de fer rendent de réels services aux populations et favorisent le développement de l'économie. Ils ont aussi leur faiblesse : leur lenteur d'autant plus sensible que la vitesse augmente sur les grands réseaux, leur matériel peu confortable, leur voie parfois sommairement entretenue, d'où des accidents et les irrégularités dans le service, leurs caractéristiques originelles de tracé (courbes) et de profil (rampes) difficilement perfectibles et à quel coût ! La situation des réseaux résulte en 1911 d'un demi-siècle au cours duquel départements et communes ont accordé des concessions.

\section{. Réseaux de CFIL et TVM}

\section{$>$ De la concession à la mise en service (fig. 6 et 7)}

Peu de conseils généraux ont conçu dès l'origine un réseau en en confiant l'exécution à un seul concessionnaire. Généralement les élus prenaient des décisions, étalées dans le temps, de construction de lignes confiées à un ou à plusieurs concessionnaires. En outre, des regroupements se sont opérés. Aussi paraît-il plus significatif d'observer le nombre d'exploitants, entreprises et particuliers, en 1911, que celui des concessions octroyées dans le même département. Dans neuf départements possédant presque tous une grande ville ou de fortes populations ouvrières, le nombre des opérateurs, renforcé par les demandes de concessions de TV, dépasse dix (Loire, Gironde, Rhône) pour culminer à 26 dans le Nord. À l'opposé, dans 38 départements à dominante rurale, on compte de un à trois opérateurs (Deux-Sèvres, Jura, Lot).

Toutes les concessions n'arrivent pas à bonne fin ; une analyse de l'état d'avancement des réseaux est nécessaire ; elle peut être conduite à travers un taux d'exécution exprimé par le rapport km réalisé/km concédé. Des exemples sont indispensables pour étayer la présentation.

On constate pour les CFIL (fig. 6) des taux de $100 \%$ dans 22 départements, de 90 à $99 \%$ dans 16 ; dans $43 \%$ des départements, soit les travaux sont très avancés, soit les lignes sont en service. Le kilométrage concédé n'a pas d'influence sur le taux d'exécution : on enregistre des taux de $100 \%$ pour quatre $\mathrm{km}$ dans les Alpes-Maritimes, sept en Côte-d'Or, mais aussi 276 km dans les Bouches-du-Rhône et 300 en Saône-et-Loire. Le kilométrage ne joue pas davantage pour des taux 


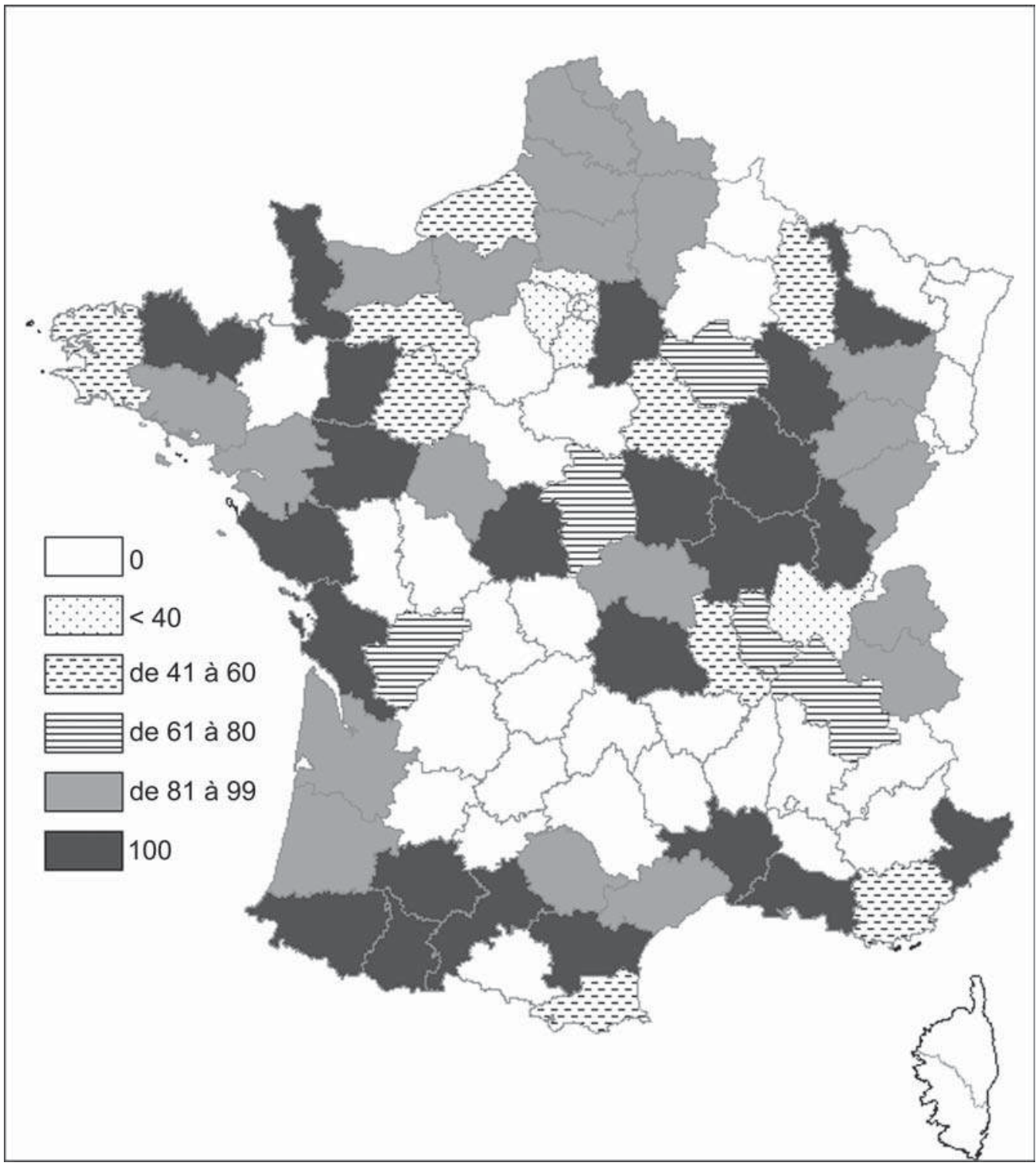

Figure 6. Pourcentage réalisé / longueur concédée des chemins de fer d'intérêt local au 31/12/1911 (\% par département). @ M. Wolkowitsch / E. Auphan (UMR CNRS PRODIG), mai 1999 - Fond de carte InterCarto. 


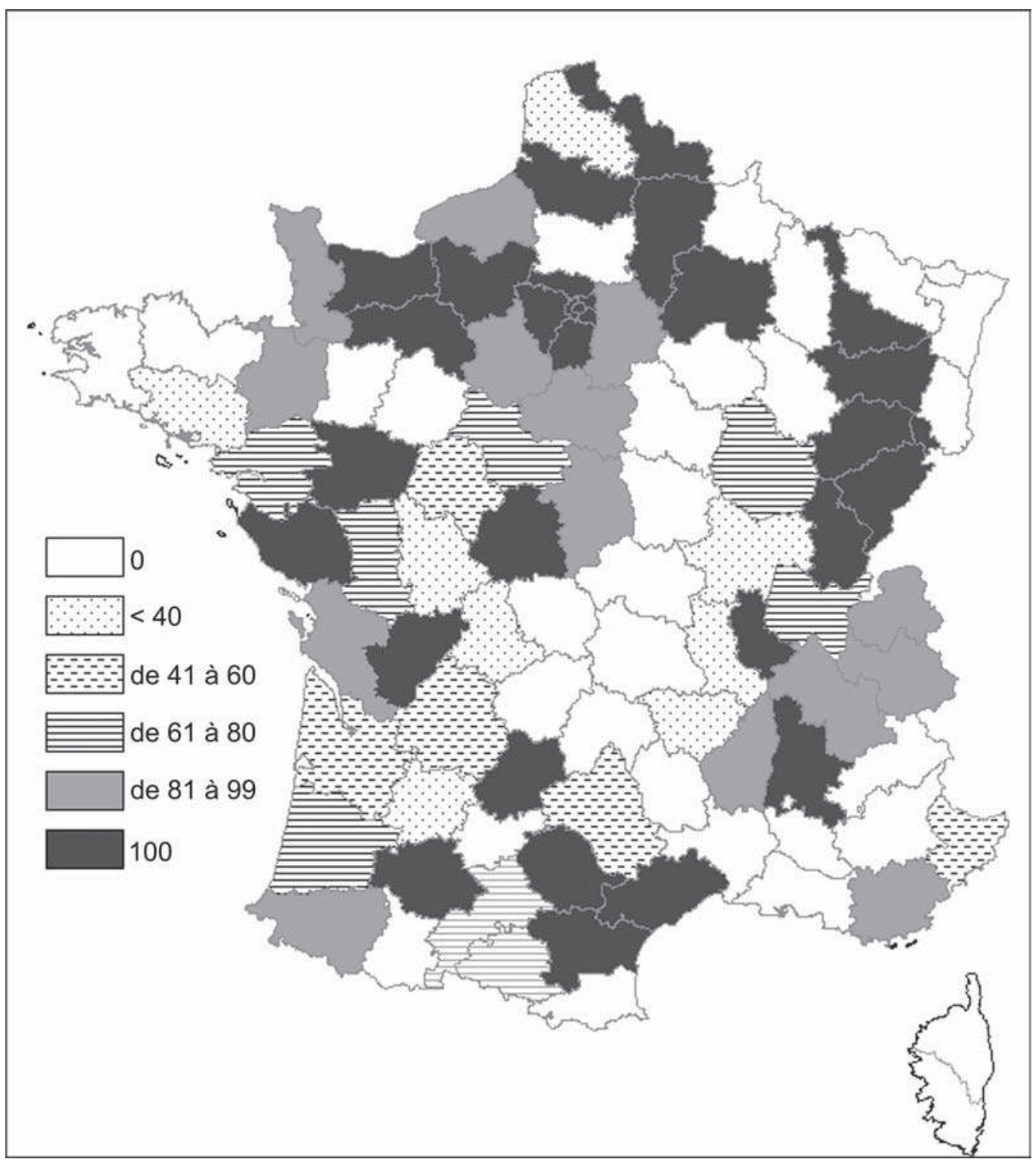

Figure 7. Pourcentage réalisé / longueur concédée des tramways voyageurs et marchandises au 31/12/1911 (\% par département). @ M. Wolkowitsch / E. Auphan (UMR CNRS PRODIG), mai 1999 Fond de carte InterCarto. 
moins élevés : $29 \%$ pour $202 \mathrm{~km}$ en Seine-et-Oise, $36 \%$ pour $30 \mathrm{~km}$ dans l'Ain, $56 \%$ pour $30 \mathrm{~km}$ dans l'Orne, également pour $335 \mathrm{~km}$ dans la Meuse.

Des observations similaires peuvent être faites pour les TVM, malgré leurs conditions plus avantageuses de construction et d'exploitation, qui pouvaient faire penser que les projets étaient plus aisément menés à leur terme (fig. 7). 24 départements offrent des taux de $100 \%$, dix de $90 \%$ à $99 \%$; cela représente $39 \%$ des départements où l'équipement est réalisé ou sur le point de l'être. L'indifférence au kilométrage concédé est aussi nette que dans le cas des CFIL. On note pour les TVM $100 \%$ pour dix km dans le Lot, 27 dans les Vosges, 239 dans le Calvados et 315 dans l'Aude. La situation est identique si on examine des taux faibles : $5 \%$ pour $18 \mathrm{~km}$ en Saône-et-Loire, $24 \%$ pour $29 \mathrm{~km}$ en Haute-Loire, même taux pour $214 \mathrm{~km}$ dans la Vienne, $16 \%$ pour $361 \mathrm{~km}$ en Haute-Vienne.

Le taux d'exécution de $100 \%$ se vérifie pour plus des deux tiers des réseaux de TV; il ne s'abaisse pas en dessous de $75 \%$; cette situation plus favorable que dans les cas précédents s'explique aisément par la relative facilité de construction de ces réseaux, par leur nécessaire adaptation à la croissance spatiale des villes qui impose de nouvelles concessions : il est significatif que des taux de l'ordre de 80 à $90 \%$ se rencontrent dans la Seine, dans les villes du Nord, puis Lyon, Marseille, Bordeaux, Nice, beaucoup plus rarement dans les villes assoupies. Un seul projet de tramway était resté sans suite à Nevers.

Il est évident qu'entre une concession accordée depuis un an et une autre octroyée depuis plusieurs années, le taux d'exécution ne saurait être le même; mais notre propos visait simplement à dresser un état des lieux à un moment donné et non à apprécier comment les concessionnaires respectaient ou non leurs engagements.

Les cartes permettent de prendre en compte la distribution géographique des taux d'exécution. Dans 32 départements n'opèrent qu'une entreprise ou plusieurs, mais relevant toutes d'un même régime juridique : absence de concession de CFIL en Ille-et-Vilaine, dans les Deux-Sèvres, le Loiret ou le Loir-et-Cher ; absence de TVM dans la Mayenne, la Sarthe, l'Allier... La carte des TVM révèle une longue trâ̂née grossièrement nord-sud sans réseau traversant la France des Ardennes aux Bouches-du-Rhône; celle des CFIL montre, au sud d'une ligne allant de la Loire-Inférieure à l'Isère, un vaste ensemble peu desservi, à l'exception des littoraux atlantique et méditerranéen dont tous les départements sont solidement pourvus en réseaux exécutés, rarement moins de $80 \%$ (Var et Pyrénées-Orientales). 
CFIL et TVM coexistent dans 47 départements; cette dualité correspond souvent au prolongement d'une ligne d'un département voisin sur quelques kilomètres; dans les autres cas les concessions ont toujours favorisé un régime, cela se traduit dans le déséquilibre des concessions : Maine-et-Loire, CFIL, 286 km ; TVM, 28 ; Jura, 30 et 142 ; le Nord fait exception avec 375 et $326 \mathrm{~km}$.

L'inégale distribution géographique des kilomètres concédés est à souligner : CFIL et TVM confondus, le kilométrage est inférieur à $50 \mathrm{~km}$ dans huit départements. Il dépasse $500 \mathrm{~km}$ dans six départements.

\section{$>$ Le réseau exploité}

\section{Longueur par département (fig. 8)}

Le réseau exploité est inégalement développé suivant les départements : le kilométrage s'échelonne entre 2 et $649 \mathrm{~km}, 26$ et 25 départements sont dépourvus de CFIL ou de TVM. Une compensation s'établit entre ces réseaux, aussi le nombre de départements sans chemins de fer secondaires n'est-il que de neuf. Les cartes reproduisent les grands traits du réseau concédé, sans en être le calque compte tenu des lignes restant à construire : l'exemple de la Sarthe avec $309 \mathrm{~km}$ exploités pour 566 concédés est significatif.

Les neuf départements privés de réseaux secondaires sont, sauf un, en zone de montagnes ou de hauts plateaux accidentés de profondes vallées (Alpes du Sud, Massif central); le coût de construction des infrastructures dépasse de $20 \%$ celui consenti en terrains plats ; l'évocation des viaducs des Fades ou de Garabit sur les grands réseaux illustre le propos. Ces départements sont pauvres; ils se sont satisfaits des lignes d'intérêt général dont le financement épargnait le budget des collectivités territoriales. Ces départements étaient peu peuplés, trois comptaient moins de 130000 habitants, un seul plus de 300 000, les densités oscillaient entre 15 et 64 habitants au $\mathrm{km}^{2}$, le déclin démographique décennal se situait entre - 2,8\% et - $6,9 \%$; la moitié des préfectures ne comptait pas 20000 habitants, dont trois moins de 10000 (Digne, Guéret, Mende). Toutes ces données expliquent, pour les uns, l'absence de demande de concession (Basses et Hautes-Alpes, Cantal, Corse, Creuse, Lozère) ; pour les autres, le retard dans les réalisations : la Corrèze (305 000 habitants) bénéficie d'un réseau de $174 \mathrm{~km}$ mis en service en 1912, le Tarn-et-Garonne, plus tard.

Douze départements ont un réseau de TVM et CFIL confondus compris entre 1 et $50 \mathrm{~km}$; vingt départements disposent de plus de $300 \mathrm{~km}$ dont six plus de 400, mais on en chercherait vainement les points communs : peut-on imaginer trois espaces plus différenciés que l'Isère 


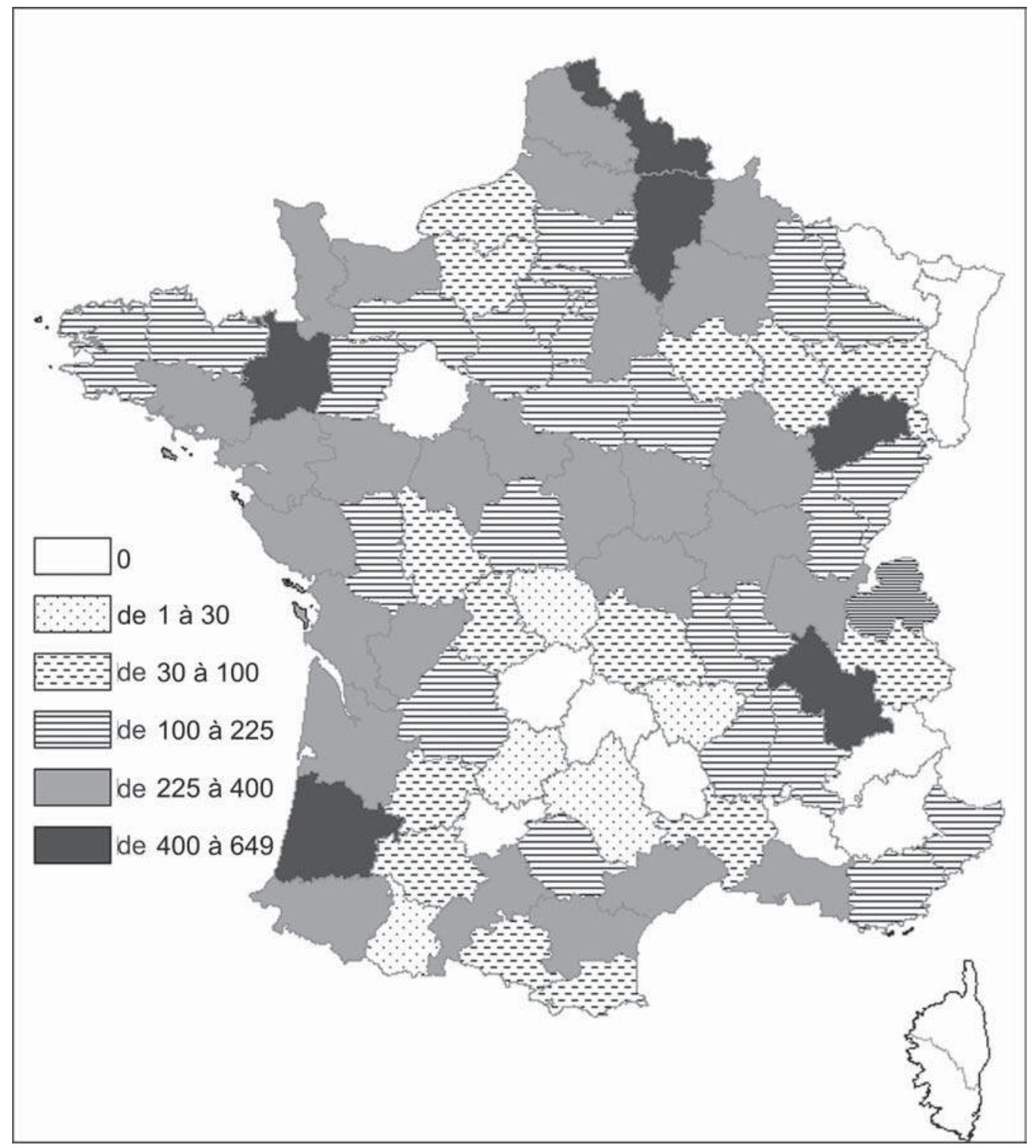

Figure 8. Longueur des chemins de fer secondaires par département en 1911 (CFIL et TVM, en km). (C) M. Wolkowitsch/E. Auphan (UMR CNRS PRODIG), janvier 1999 - Fond de carte InterCarto. 
(524 km), les Landes (499) et le Nord (649) ? Le milieu naturel montre une plaine landaise parfaite, une plaine des Flandres troublée de modestes collines, un ensemble alpin offrant avec les massifs de la Chartreuse et de Belledonne et la vallée du Grésivaudan la diversité de ses aspects. La population connaît des évolutions démographiques divergentes et les densités sont parmi les plus faibles et les plus fortes de France, hors cas particuliers (Seine et Territoire de Belfort). Le milieu économique présente une région industrielle majeure, un département dominé par l'économie forestière, une montagne d'où les archaïsmes agraires en altitude n'ont pas disparu tandis que les vallées s'animaient d'industries fondées sur la production d'électricité. Restent 46 départements, huit comptent entre 51 et $100 \mathrm{~km}, 38$ se situent dans la fourchette 101$300 \mathrm{~km}$.

Kilomètres exploités pour 100000 habitants et $100 \mathbf{k m}^{2}$ (fig. 9 et 10)

Rappelons les différences de superficies entre départements dans un rapport allant de un à plus de trois (Rhône : $2856 \mathrm{~km}^{2}$; Gironde : 9 778), celle de population de un à près de 20 (Hautes-Alpes : 100000 habitants ; Nord : 2 millions). Pour affiner la connaissance des réseaux ces réalités doivent être prises en compte : le degré d'équipement d'un territoire peut se traduire en $\mathrm{km} / 100 \mathrm{~km}^{2}$; l'efficacité du réseau dont les hommes peuvent disposer, en km/100 000 habitants. Un classement des départements peut alors être proposé en se fondant sur la combinaison des indices, des comparaisons peuvent être faites, une explication de la répartition géographique des réseaux peut être tentée. Les cartes de densité des réseaux répondent à notre attente.

Treize départements offrent des indices ne dépassant pas $1 \mathrm{~km} /$ $100 \mathrm{~km}^{2}$ et $25 \mathrm{~km} / 100000$ habitants ; cela correspond à une irrigation limitée du territoire et à un développement insuffisant du réseau pour la population desservie. Les réseaux comptent entre 3 et $60 \mathrm{~km}$. Hors le Puy-de-Dôme et le Gard, ces départements ont un volume de population peu étoffé ; onze d'entre eux, profondément ruraux, sont affectés d'une régression démographique décennale très élevée ; la densité de population varie entre 34 et 70 habitants au $\mathrm{km}^{2}$. Les villes évoluent peu sauf si elles bénéficient d'un réel dynamisme industriel (ClermontFerrand, Limoges). Hors l'Eure, l'Aube et la Haute-Marne, ces départements souvent en partie montagneux se situent dans le Massif central et ses marges ou occupent des espaces aquitains et pyrénéens (tabl. 58). 


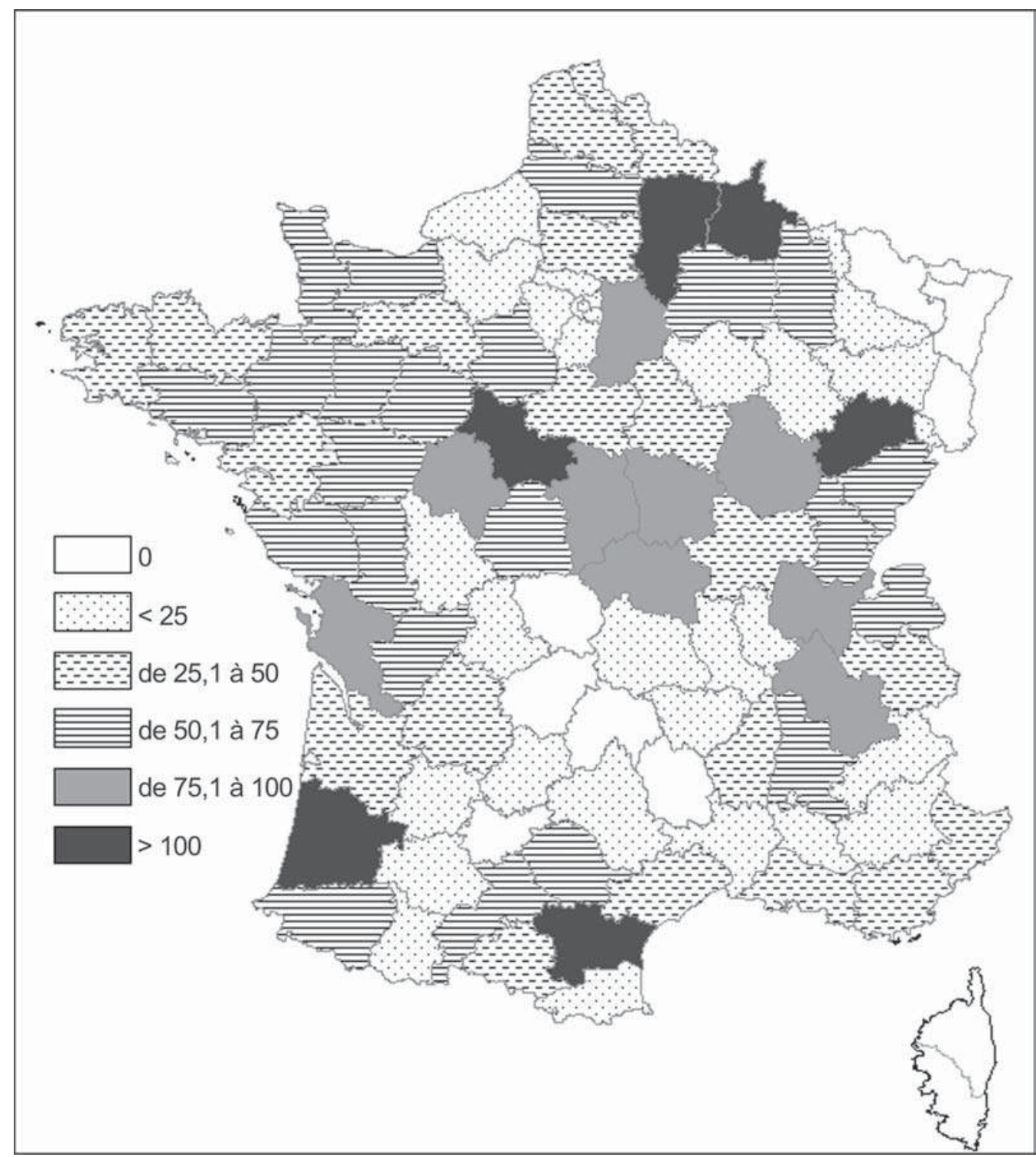

Figure 9. Densité de chemins de fer secondaires par département au 31/12/1911 (CFIL et TVM, km/ 100000 habitants). @ M. Wolkowitsch / E. Auphan (UMR CNRS PRODIG), février 1999 - Fond de carte InterCarto. 


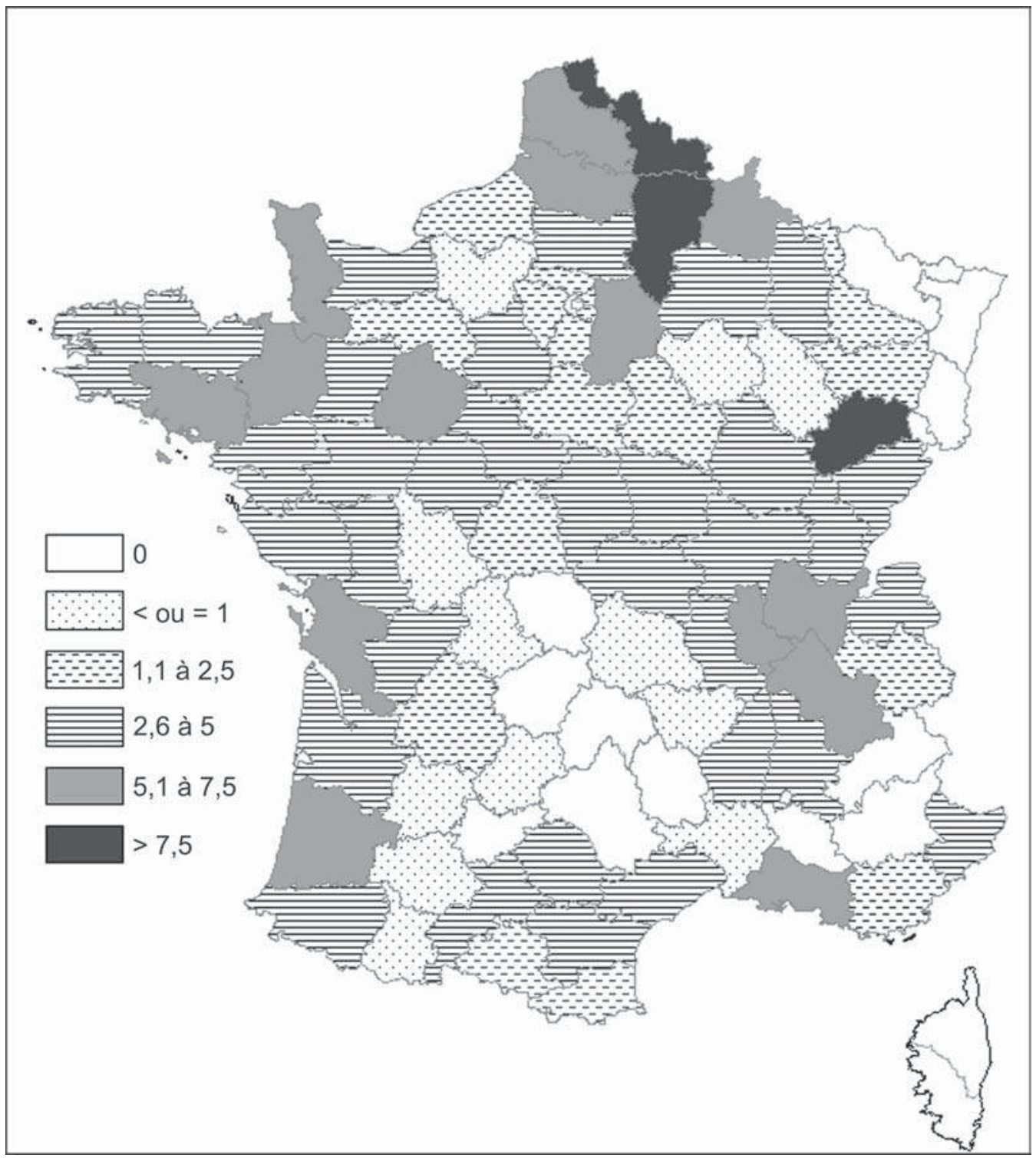

Figure 10. Densité de chemins de fer secondaires par département au 31/12/1911 (CFIL et

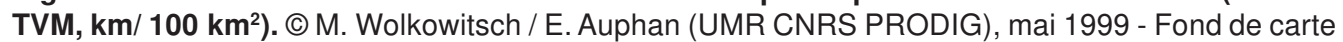
InterCarto. 

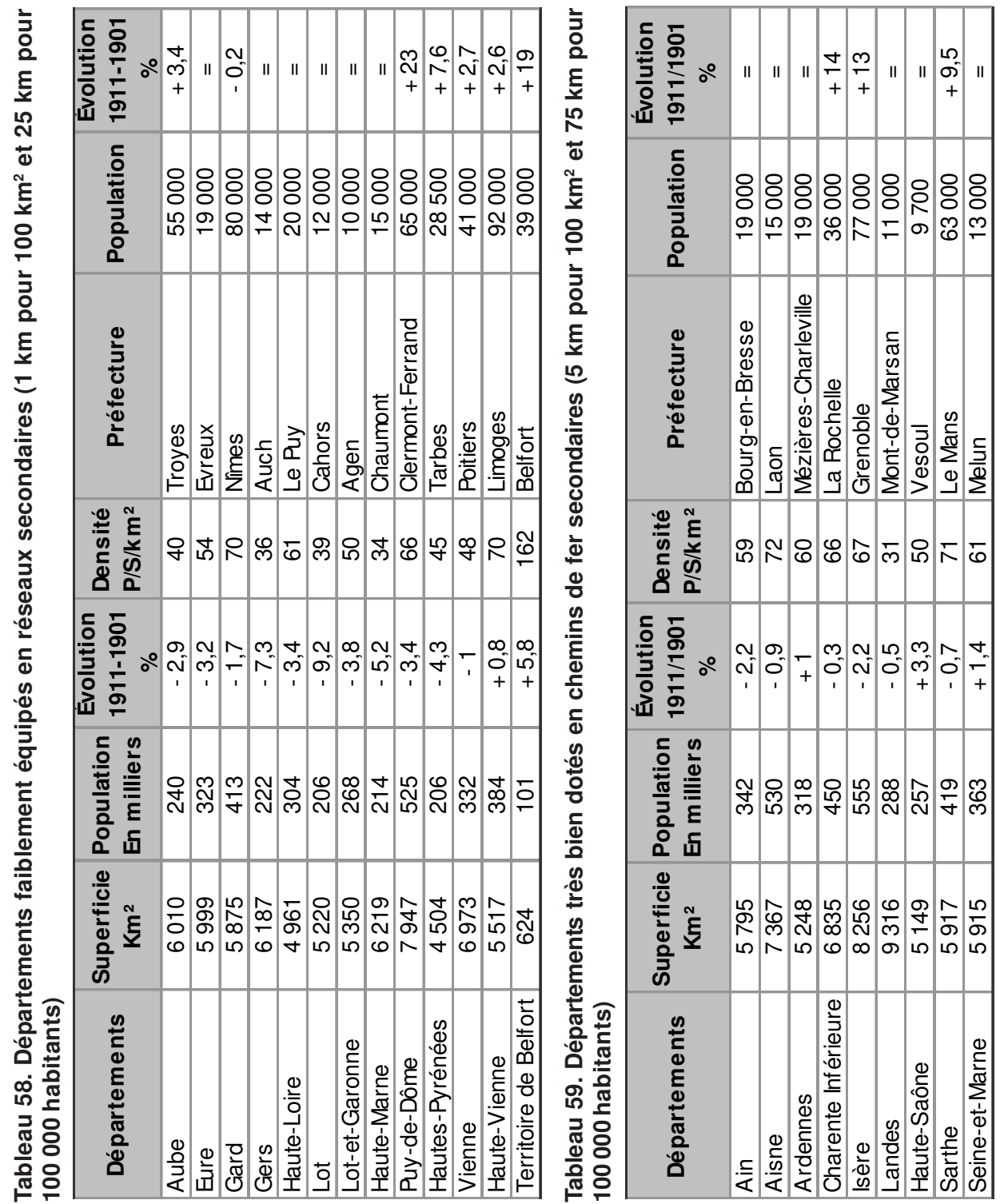
Neuf départements ont des indices supérieurs à $5 \mathrm{~km} / 100 \mathrm{~km}^{2}$ et $75 \mathrm{~km} / 100000$ habitants, traduisant un très bon équipement (tabl. 59). Les réseaux comptent entre 308 et $565 \mathrm{~km}$. Quatre de ces départements dépassent 400000 habitants. La régression démographique est moins sensible que dans le groupe précédent et épargne deux départements. La densité de population s'abaisse à $31 \mathrm{hab}$. $/ \mathrm{km}^{2}$ dans les Landes, mais s'élève au dessus de 60 dans sept cas. La Rochelle, Le Mans et Grenoble progressent face à des cités de moins de 20000 habitants, endormies. Constatons la dispersion de ces départements. La présence inattendue des Landes s'explique par la volonté de sortir ce département d'un véritable sous-développement: l'économie forestière supposait des transports difficiles à assurer avec le roulage à une certaine distance. Les facilités de construction offertes par le relief aidant, les voies ferrées ont été multipliées. Le cas de la Haute-Saône est à souligner, car rien ne prédisposait ce département à figurer dans le peloton de tête, sinon le dynamisme de la Compagnie générale des chemins de fer vicinaux qui a reçu un monopole de fait du conseil général.

L'analyse des cartes indique une série de départements dont les indices sont au-dessus de la moyenne, et où une entreprise domine la construction, puis l'exploitation du réseau; ce rôle a été tenu par la SGCFE dans l'Allier et la Nièvre (contrôle exercé à $90 \%$ ), et par la Compagnie des chemins de fer du Sud-Ouest en Haute-Garonne, à $96 \%$; les exemples sont sans fin: Manche $95 \%$, Morbihan $95 \%$, Ardennes et Sarthe $85 \%$... La présence d'une entreprise maitresse dans un département est un facteur favorable au développement du réseau.

La carte signale également six départements (Nord, Pas-de-Calais, Somme, Aisne, Ardennes, Seine-et-Marne) bénéficiant de plus de $5 \mathrm{~km} /$ $100 \mathrm{~km}^{2}$ et formant un ensemble cohérent; si on prend en compte la population, les indices $\mathrm{km} / 100000 \mathrm{hab}$. des départements les plus peuplés sont nettement moins favorables. Ce noyau proche de la frontière a subi une influence belge sous forme de capitaux et d'expérience acquise dans ce type de chemins de fer.

Si nous considérons maintenant l'ensemble des départements présentant des indices $\mathrm{km} / 100 \mathrm{~km}^{2}$ forts, face à des indices $\mathrm{km} / 100000$ habitants faibles, nous retrouvons le Nord et le Pas-de-Calais (tabl. 60). Tous ces départements, à l'exception des Alpes-Maritimes peu étendu, comptent plus de 600000 habitants, de fortes densités de population, une évolution démographique positive sauf dans la Loire, de grandes préfectures en progrès, à l'exception d'Arras à la tête d'un département minier avec une population dispersée. Une forte population fait baisser 


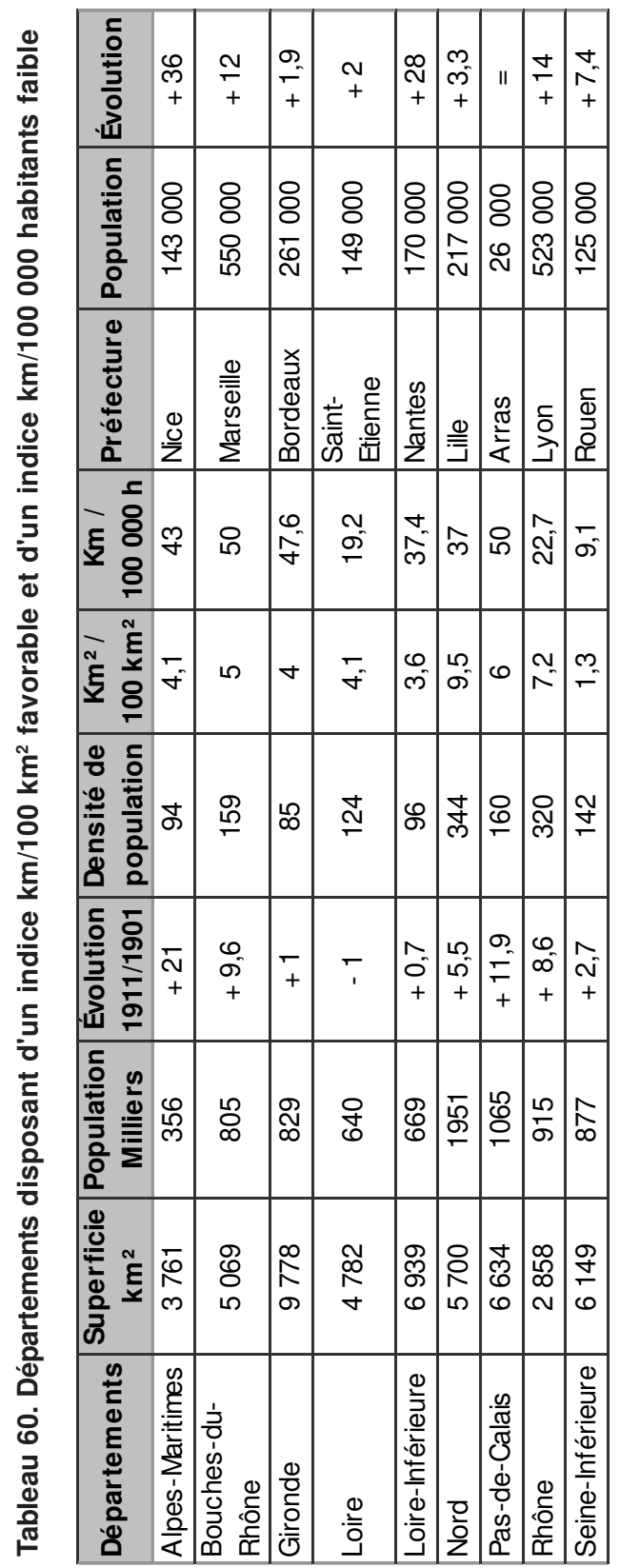


l'indice $\mathrm{km} / 100000$ hab., mais la couverture territoriale étant satisfaisante, la population bénéficie de services valables, si le réseau est intensément utilisé. On est surpris de ne pas trouver dans ce groupe la Seine-Inférieure dont les caractéristiques démographiques et économiques, les activités industrielles et portuaires offrent bien des traits communs avec les départements étudiés; l'explication tient au développement du réseau ferré d'intérêt général qui représente $80 \%$ des voies ferrées départementales, réduisant l'appel aux chemins de fer secondaires qui ne comptent que $1,3 \mathrm{~km} / 100 \mathrm{~km}^{2}$.

La qualité de la desserte pour les usagers dépend de la totalité des lignes en service, celles des réseaux d'intérêt général incluses ; ces derniers se sont étoffés, grâce au plan Freycinet, parallèlement à l'extension des réseaux secondaires. Les réseaux d'intérêt général et secondaire représentent respectivement 60 et $40 \%$ du réseau ferré français ; aussi la carte souligne-elle la prédominance des départements où la part des grands réseaux se situe au-dessus de $60 \%$ (fig. 11); elle ne s'abaisse en dessous de $50 \%$ que rarement (Isère : $41 \%$; Allier et Haute-Saône : $48 \%$ ) ; elle atteint $100 \%$ dans des départements où le chemin de fer s'est peu étendu : $376 \mathrm{~km}$ dans le Cantal, 361 dans la Creuse, 182 dans les Hautes-Alpes, alors que la moyenne par département tous réseaux confondus s'établit à $681 \mathrm{~km}$ et à $468 \mathrm{~km}$ pour les seules lignes d'intérêt général.

\section{$>$ L'organisation spatiale des réseaux de chemins de fer secondaires}

La typologie fondée sur la densité des réseaux en fonction de la superficie et de la population doit être complétée par l'analyse de l'organisation spatiale des réseaux départementaux : le nombre de kilomètres alignés ne suffit pas. Le réseau correspond-il au mieux aux besoins des populations, son dessin assure-t-il la meilleure couverture territoriale du département?

L'étude s'appuie sur une série d'exemples illustrés par une carte ; le document comporte les tracés des lignes d'intérêt général dans leur diversité et des lignes d'intérêt local ; les réseaux de transport urbain de voyageurs n'y figurent pas. Chaque carte est l'objet d'un commentaire en deux parties : la première est consacrée au document, la seconde est une réflexion sur des cas similaires ou voisins ${ }^{11}$.

11- Ces cartes sont extraites d'une carte générale des réseaux ferroviaires français (toutes lignes construites), dont l'échelle a été adaptée aux dimensions des zones choisies et peut donc être différente pour chacune des cartes. Les lignes du réseau principal sont en gras. 


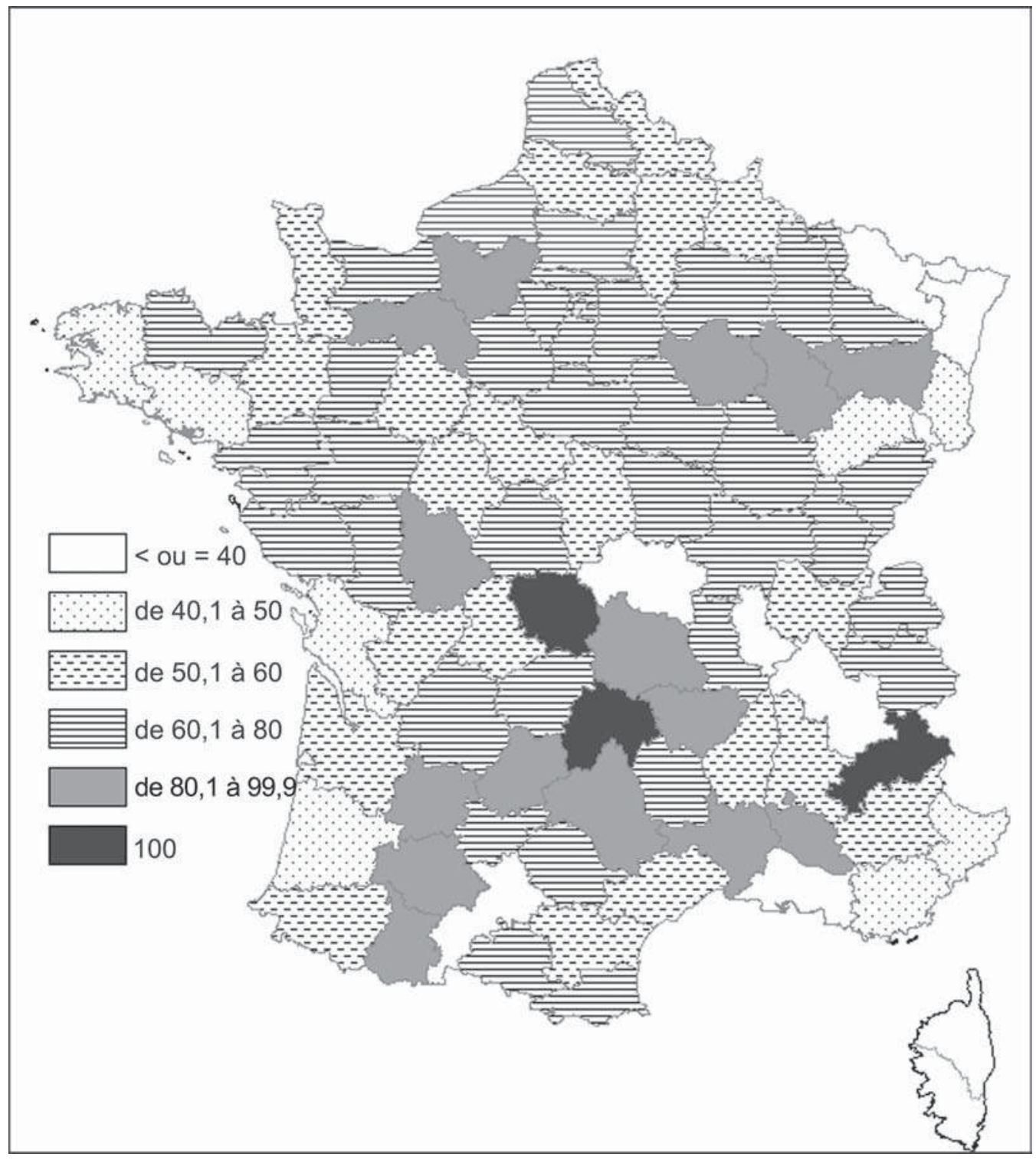

Figure 11. Pourcentage du réseau d'intérêt général dans le réseau total par département au 31/12/1911. @ M. Wolkowitsch / E. Auphan (UMR CNRS PRODIG), mai 1999 - Fond de carte InterCarto. 


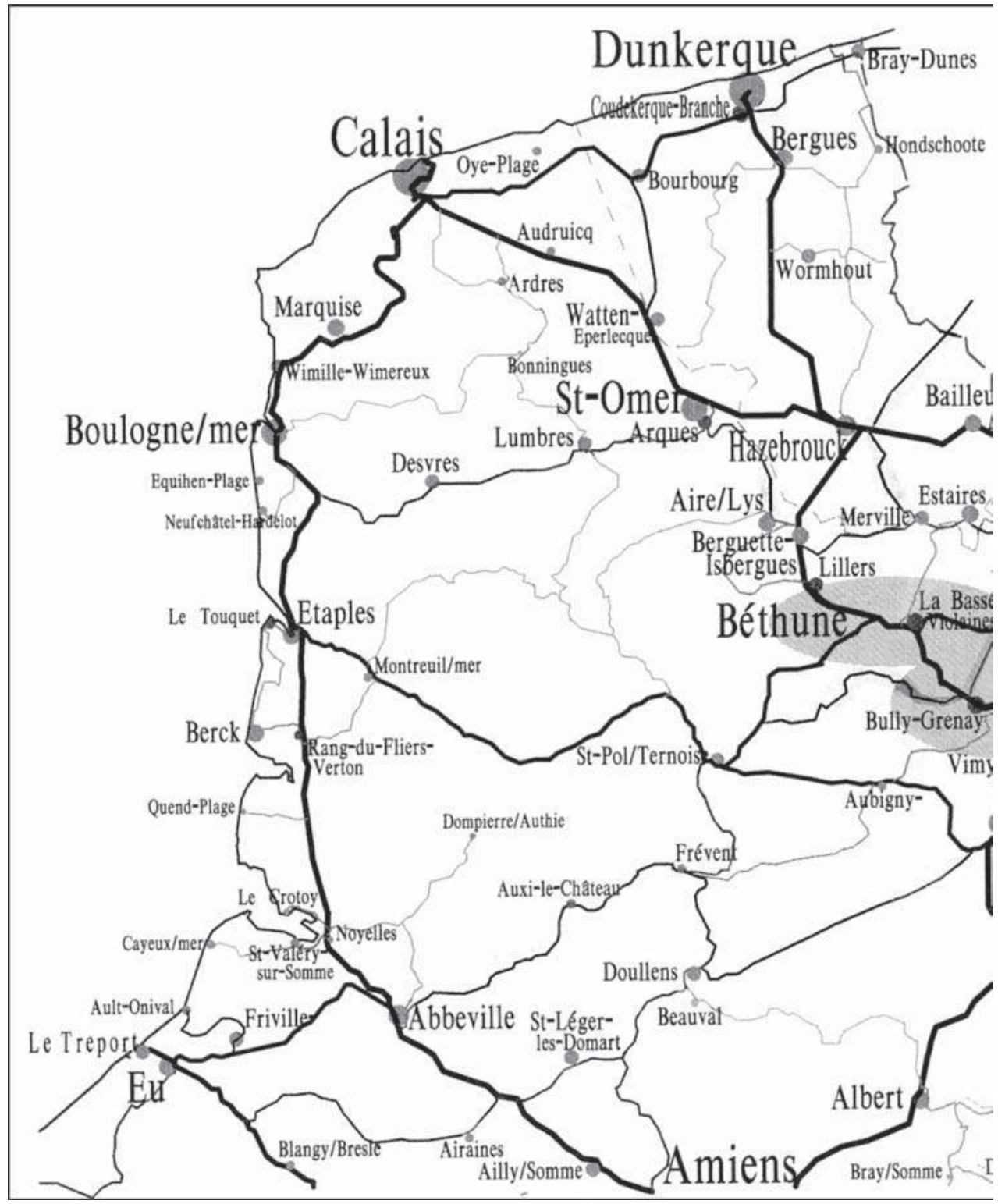

Figure 12. Le réseau ferroviaire du Nord. Toutes lignes construites avant 1993. (C) E. Auphan. Exemple type d'un réseau secondaire au cœur d'une région industrielle. 


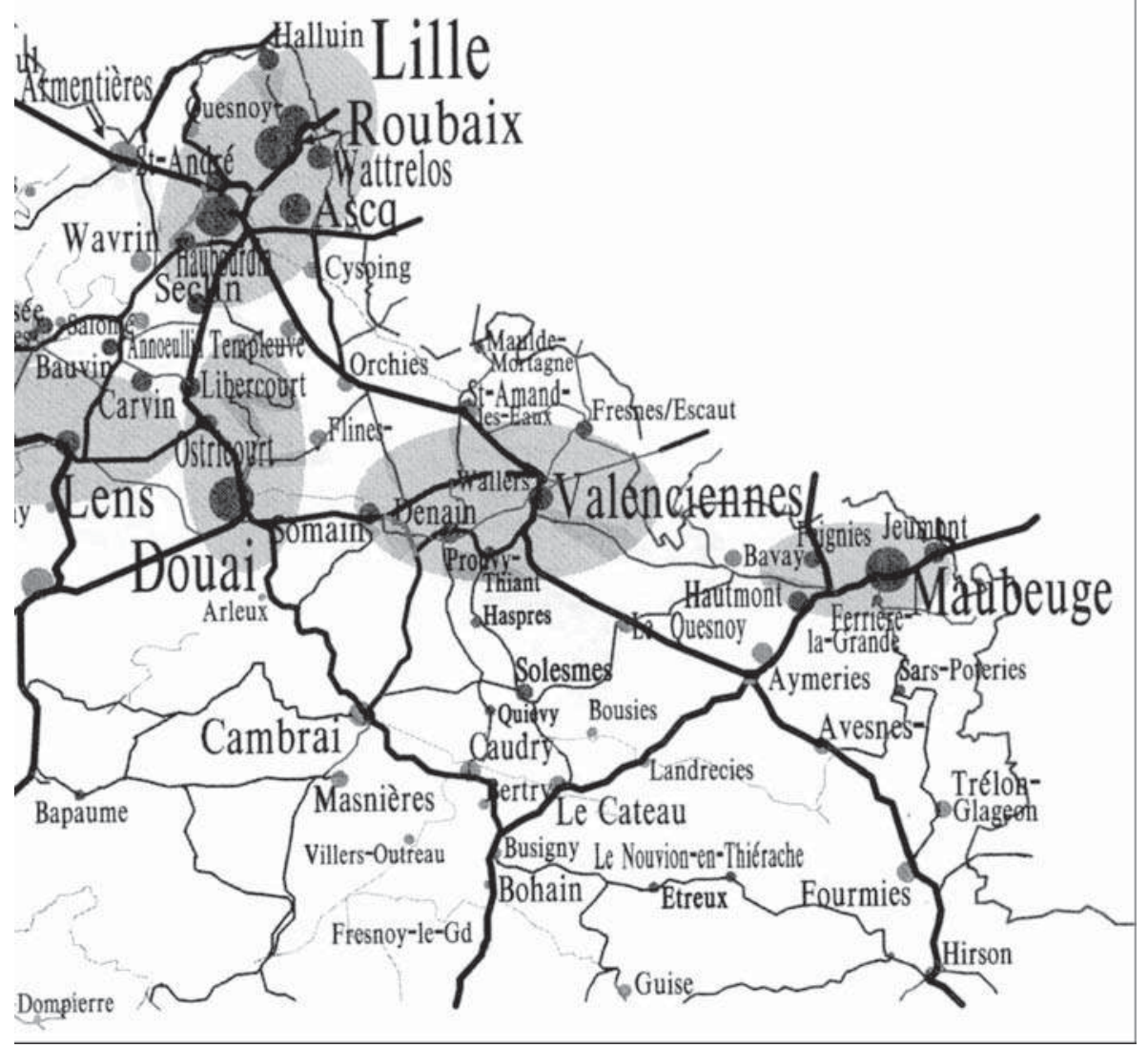




\section{Études de cas}

Le Nord (fig. 12) dispose d'un long réseau secondaire, partageant avec les lignes d'intérêt général l'acheminement de nombreux migrants pendulaires, parfois sur des distances importantes. Ces mouvements sont liés à l'industrialisation exceptionnelle de la région et aux échanges de main-d'œuvre avec le bassin minier du Pas-de-Calais. Des réseaux se sont ordonnés autour de Valenciennes, Denain, Douai et à un moindre degré Cambrai. L'agglomération lilloise, desservie par des lignes d'intérêt général et de bons réseaux de TV, est peu concernée ; quelques lignes parcourent les espaces restés ruraux.

La densité des lignes des grands réseaux divergent au départ de Paris est telle qu'elle n'a pas laissé place à des lignes secondaires dans la Seine, hors la ligne des Halles à Arpajon ; seuls sont nés des réseaux de transport urbain de voyageurs. Dans les Bouches-du-Rhône et le Rhône, Marseille et Lyon sont respectivement à l'origine de 8 et $20 \%$ des kilomètres de chemins de fer secondaires parcourant ces départements; les lignes rurales dominent. Autour des plus grandes villes, le développement du réseau d'intérêt général limite celui des chemins de fer secondaires.

La Sarthe dispose d'un réseau de cinq lignes (fig. 13) qui, avec les bifurcations, établissent huit liaisons entre la préfecture, Le Mans, et sa circonscription : les déplacements vers la ville et en sens inverse sont aisés. Les lignes parcourent les espaces oubliés par l’Ouest-État. Hors Le Mans n'existe pas d'autre convergence majeure.

Les réseaux de Charente, Dordogne et Ille-et-Vilaine s'apparentent à celui de la Sarthe ; une même préoccupation de combler les vides laissés entre les lignes d'intérêt général est manifeste. On retrouve en HauteGaronne un réseau étoilé assurant six liaisons : contrairement à Lyon et à Marseille, Toulouse moins peuplée est à l'origine de $85 \%$ des kilomètres des lignes secondaires. Le réseau de Haute-Saône montre quatre directions au départ de Vesoul ; carrefour encore inachevé en 1911, puisque les lignes ont été construites entre 1907 et 1912, alors que le reste du territoire était desservi par un réseau très long dont la première mise en service datait de 1877.

La Nièrre (fig. 14) a pour limite occidentale du Sud au Nord successivement l'Allier, puis la Loire ; Nevers attirée par le fleuve est devenue la préfecture malgré une position excentrée ; une ligne unique s'en échappe vers Saint-Saulge où elle se coupe en deux ${ }^{12}$; la couverture du département est très imparfaite.

12- L'une se dirige vers Tamnay-Châtillon, l'autre vers Saint-Révérien et Corbigny. 


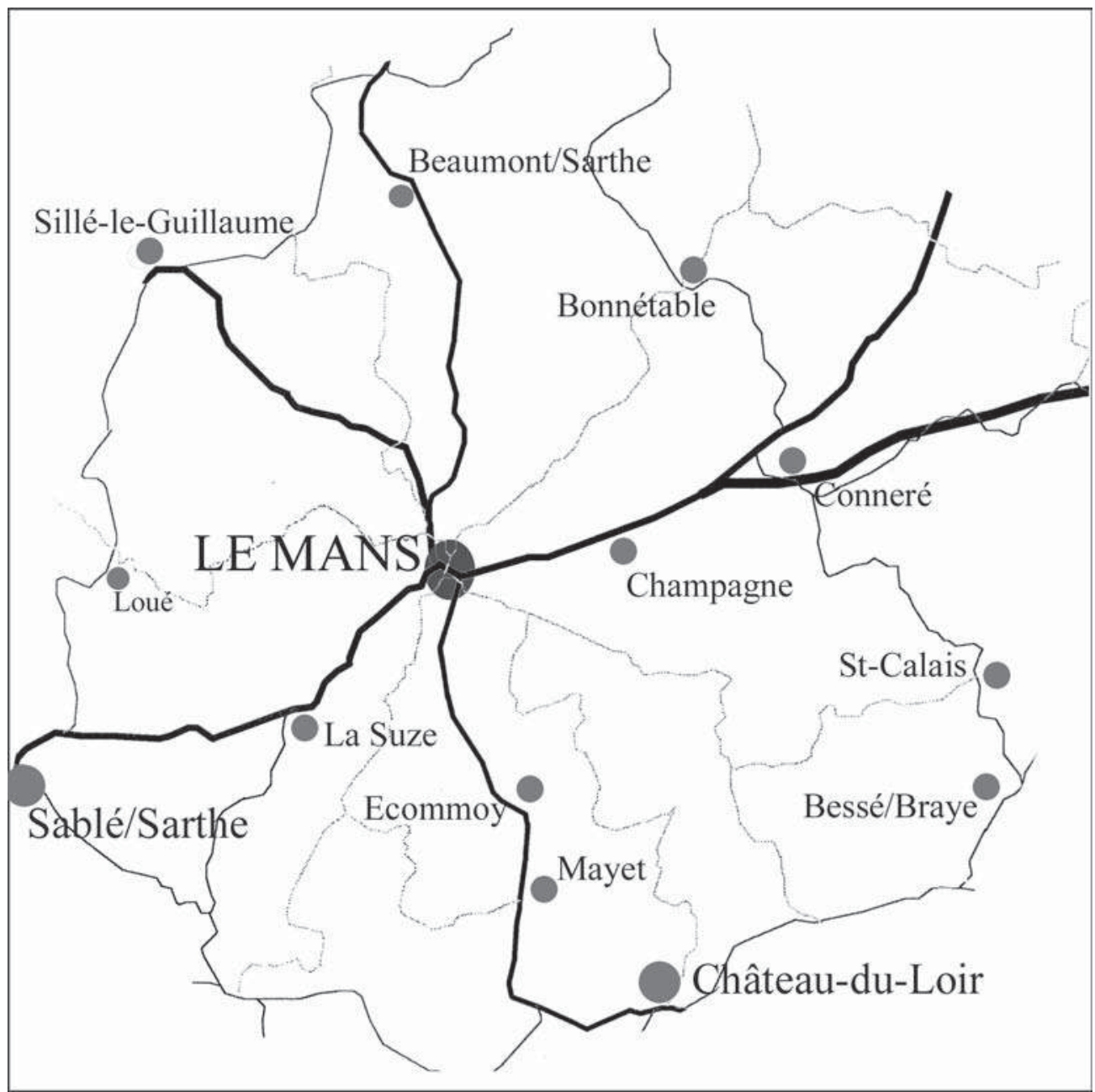

Figure 13. Le réseau ferroviaire de la Sarthe. Toutes lignes construites avant 1989. ( E. Auphan. Le réseau secondaire rayonnant autour de la préfecture assure une bonne couverture du territoire départemental. 


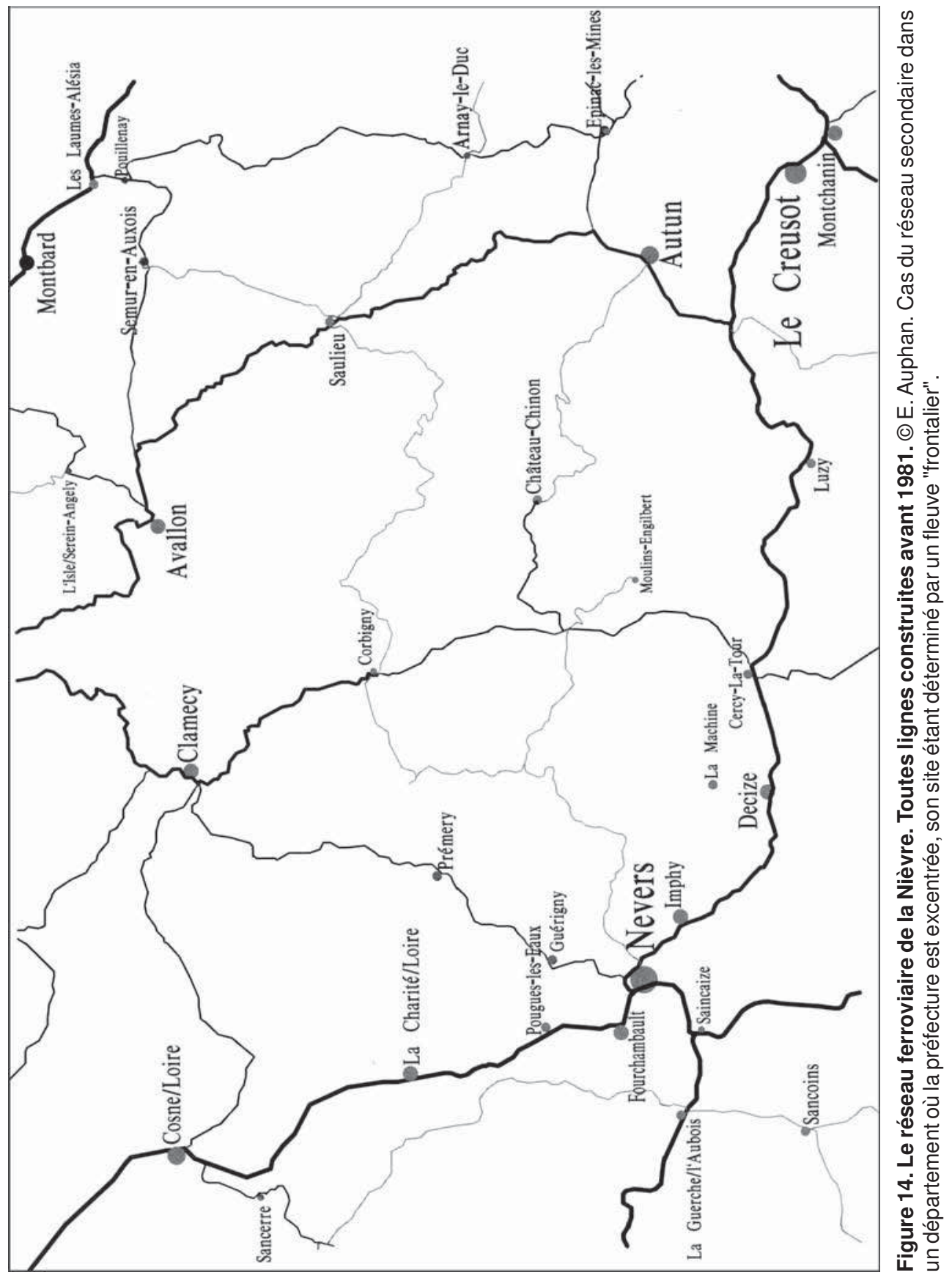


Les ports de mer, les préfectures situées sur un fleuve, limite du département, sont déjà privées de la moitié de leur aire de rayonnement; dans les départements où la préfecture a ce type de situation géographique, elle ne sert pas de terminus à la majeure partie des lignes; on peut généralement constater l'absence ou la faiblesse des réseaux secondaires sur la partie disponible : La Rochelle, Macon, Avignon, illustrent ce propos pour la Charente-Inférieure, la Saône-et-Loire et le Vaucluse.

L'Indre (fig. 15) a un ensemble de lignes partagés entre trois compagnies : le BA (Le Blanc-Argent) circule dans l'ouest du département entre Le Blanc et Chabris, puis se prolonge dans le Cher ; sur cette ligne se greffe à Écueillé un prolongement de la ligne des CFD venue de Montrésor en Indre-et-Loire. La Compagnie des tramways de l'Indre exploite trois lignes sans terminus commun; deux relient des villes, Argenton-sur-Creuse au Blanc avec antenne vers le centre minier de Chaillac, Issoudun à Vierzon dans le Cher, Châteauroux à Valençay, chef-lieu de canton où passe le BA. La préfecture n'est terminus que d'une ligne. Même en tenant compte des lignes d'intérêt général, ni les liaisons avec Châteauroux, ni la couverture du territoire ne peuvent être considérées comme bien assurées. Malgré sa position centrale, la préfecture n'est pas le centre d'un réseau de chemins de fer secondaires.

D'autres départements ont des lignes dépendant de plusieurs compagnies, parfois géographiquement isolées, la préfecture étant peu ou pas desservie; excentrée dans les Hautes-Pyrénées (Tarbes), elle ne l'est ni en Haute-Marne (Chaumont), ni dans les Vosges (Épinal). Ce cas de figure fréquent évoque soit des réseaux inachevés, soit des réseaux jamais pensés. Une étude historique peut seule apporter la réponse.

L'Allier (fig. 16) a une préfecture en position centrale, mais une seule ligne y a son terminus (Moulins à Cosne-sur-l'Eil). Le réseau est particulièrement développé au Sud-Ouest. La SGCFE contrôle 90 \% du kilométrage exploité. Les chemins de fer secondaires sont ici mis en valeur comme affluents des lignes d'intérêt général. Les contacts sont nombreux et ont lieu dans de petites stations (Saint-Bonnet-de-Rochefort, Lapeyrouse, Bézenet, Saint-Pourçain-sur-Sioule) pour le réseau au sud-ouest du département; d'autres exemples existent entre Moulins et Digoin.

La volonté de limiter le nombre des kilomètres à construire conduisait à établir les correspondances avec les grands réseaux dans les stations les plus faciles à joindre de préférence à une ville cependant plus génératrice de trafic. Les exemples sont innombrables : la ligne de $52 \mathrm{~km}$ du Grand-Pressigny se greffe sur la ligne du PO à Esvres entre Tours et Loches, à quelques kilomètres de Tours, imposant manutention et correspondance. 


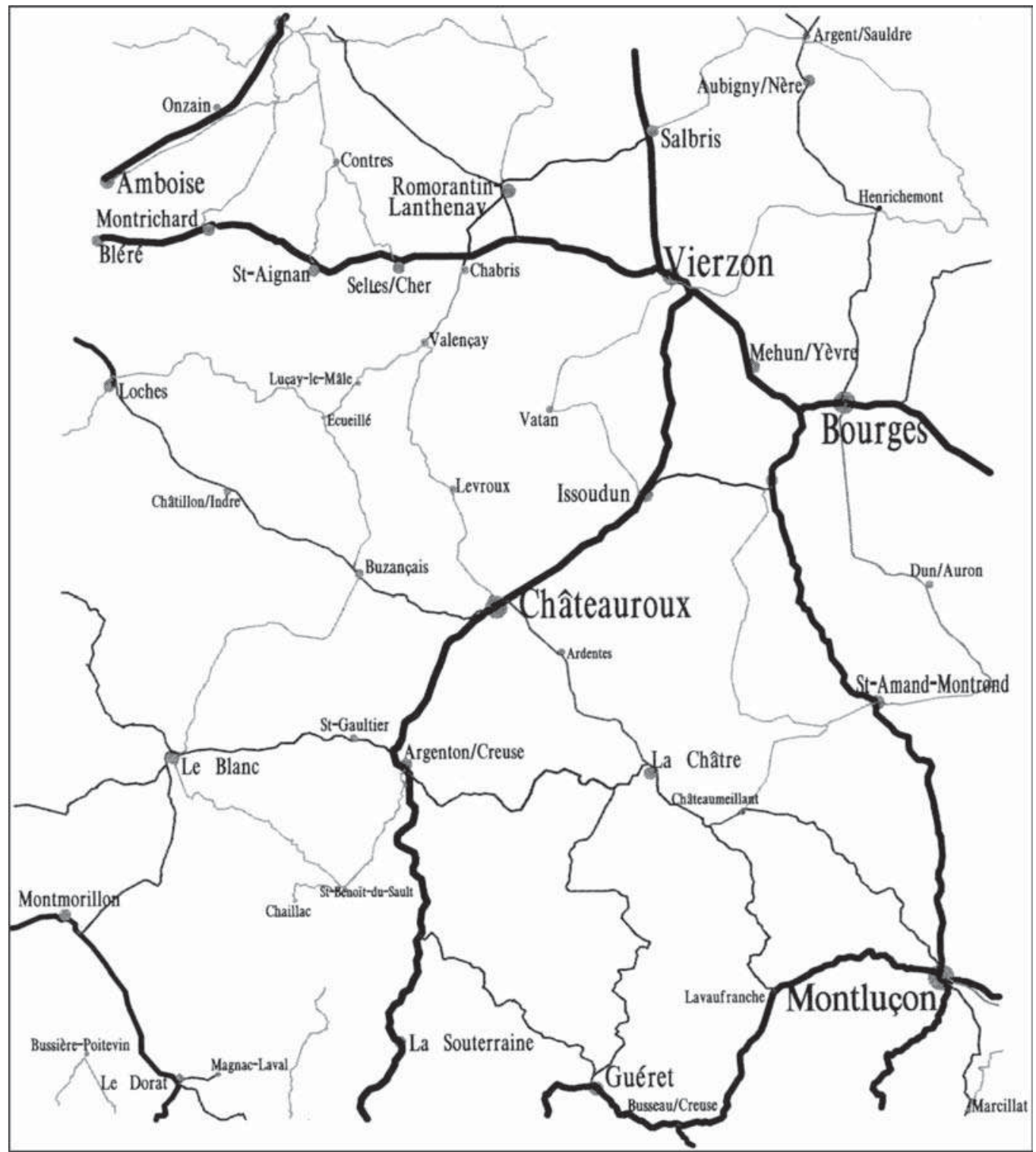

Figure 15. Le réseau ferroviaire de I'Indre et du Cher. Toutes lignes construites. (c) E. Auphan. L'Indre présente le cas d'un département où le conseil général a établi des lignes isolées et non un réseau cohérent. Le Cher offre un réseau très développé multipliant les convergences avec le réseau principal, mais Bourges ne sert de départ qu'à une ligne secondaire. 


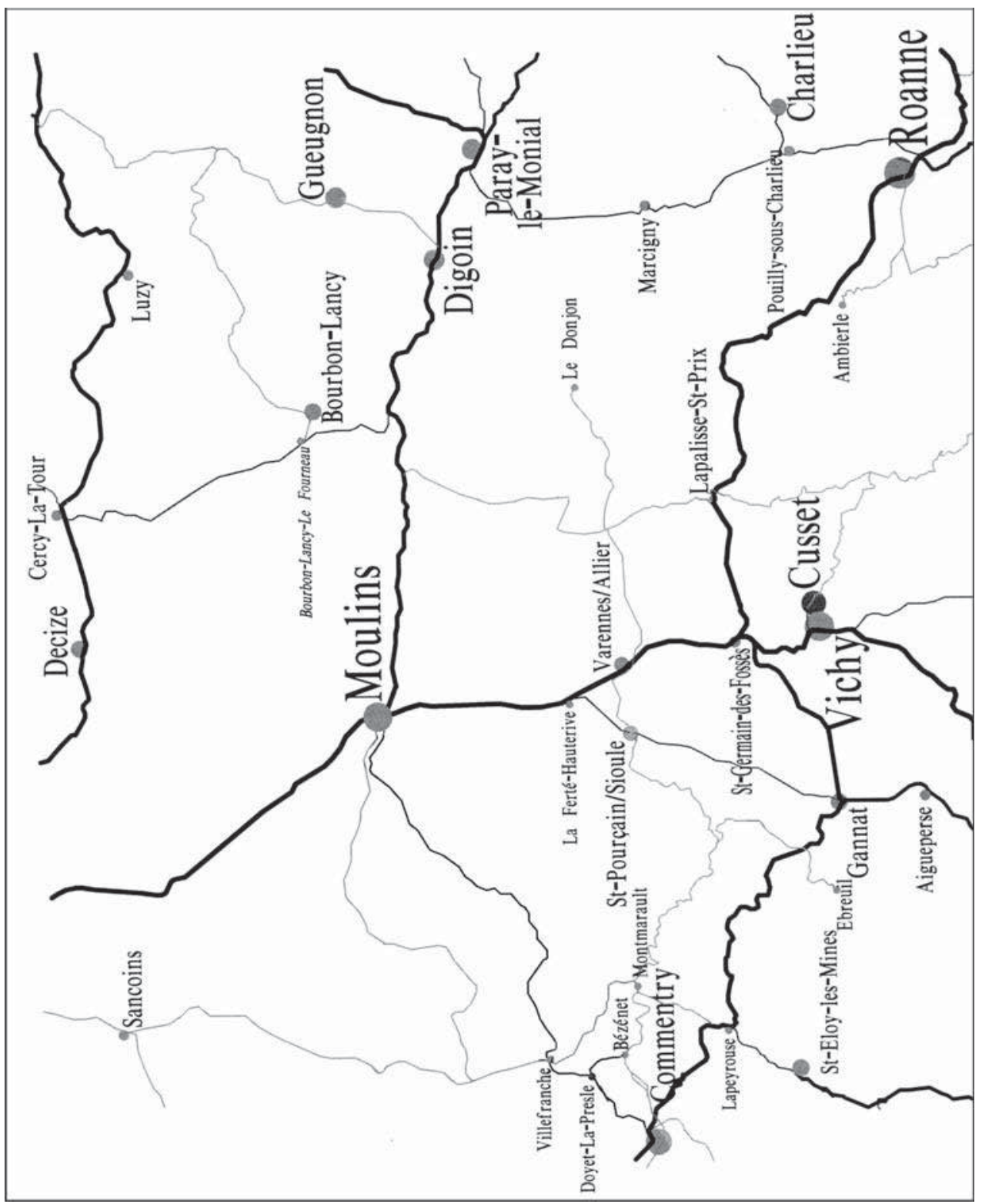

Figure 16. Le réseau ferroviaire de I'Allier. Toutes lignes construites. ㄷ E. Auphan. Le département est caractérisé par des lignes secondaires affluentes du réseau principal avec des gares de transit de faible importance. 
L'Ardèche (fig. 17) est traversé par la ligne Lyon-Nîmes longeant la rive droite du Rhône. La vallée est dominée par l'escarpe orientale du Massif central culminant à plus de 1500 mètres dans les monts du Vivarais, descendant par paliers jusqu'au fleuve. Les affluents du Rhône ouvrent autant de possibilités de pénétration. Ce département très montagneux est encore peuplé avec une densité de population de $64 \mathrm{hab} / \mathrm{km}^{2}$, avant tout rurale; la préfecture, Privas, compte moins de 8000 habitants. La desserte de cet ensemble a été réalisée par la Compagnie des chemins de fer départementaux sous le régime de lignes d'intérêt général $(178 \mathrm{~km})$ et d'intérêt local $(67 \mathrm{~km})$. Les vallées principales (Doux, Eyrieux...) sont empruntées par les voies ferrées. Si on considère l'ensemble du réseau des CFD, on voit sept lignes partant, en des points différents, de la ligne Lyon-Nîmes à l'assaut de la montagne et y pénétrant inégalement. Un vaste désert ferroviaire se dessine entre les lignes Peyraud-Dunières et Le Cheylard-Tournon. La liaison de La Voultesur-Rhône au Chambon-sur-Lignon franchit la ligne de partage des eaux Méditerranée - Atlantique. Dunières est choisi comme terminus conjoint avec le PLM qui relie cette localité à Saint-Étienne.

Le long de la retombée du Massif central, plus au nord et plus au sud de l'Ardèche, plus à l'Ouest dans l'Hérault et l'Aude, il n'y a pas de réplique du réseau du Vivarais. Le long réseau de la CFIL de l'Hérault est un réseau de plaine. À l'est du Rhône, hors la ligne d'intérêt général qui longe la Drôme, les lignes d'intérêt local pénètrent peu le Vercors et le Diois, au départ du fleuve.

Le versant nord des Pyrénées (fig. 18), à l'ouest de la chaîne, de la Haute-Garonne aux Basses-Pyrénées, offre un exemple de pénétration par de nombreuses vallées. Le Midi ayant équipé de lignes électrifiées plusieurs relations (Puyoo-Mauléon, Lannemezan-Arreau-Cadéac, Lourdes à Pierrefitte-Nestalas), les chemins de fer secondaires occupent les vallées non équipées et viennent à plusieurs reprises en complément des lignes du Midi.

La disposition des reliefs des Préalpes du Nord n'a pas donné un même schéma, caractérisé par une série de lignes isolées les unes des autres et progressant plus ou moins loin au cœur de la montagne pyrénéenne. 


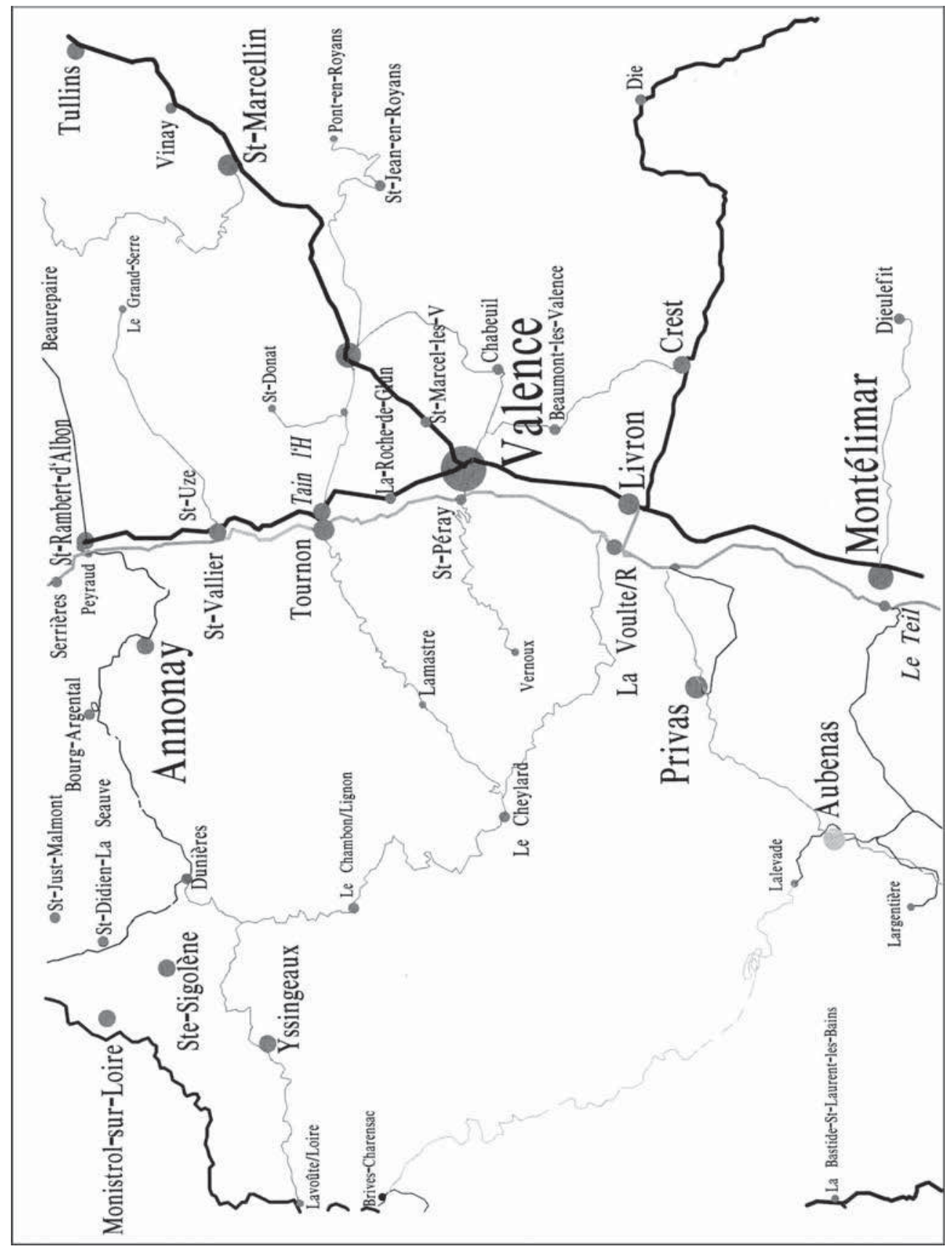

Figure 17. Le réseau ferroviaire de l'Ardèche. Toutes lignes construites avant 1994. ( E. Auphan. Chaque vallée attaquant l'escarpe orientale du Massif central fixe une voie ferrée. 


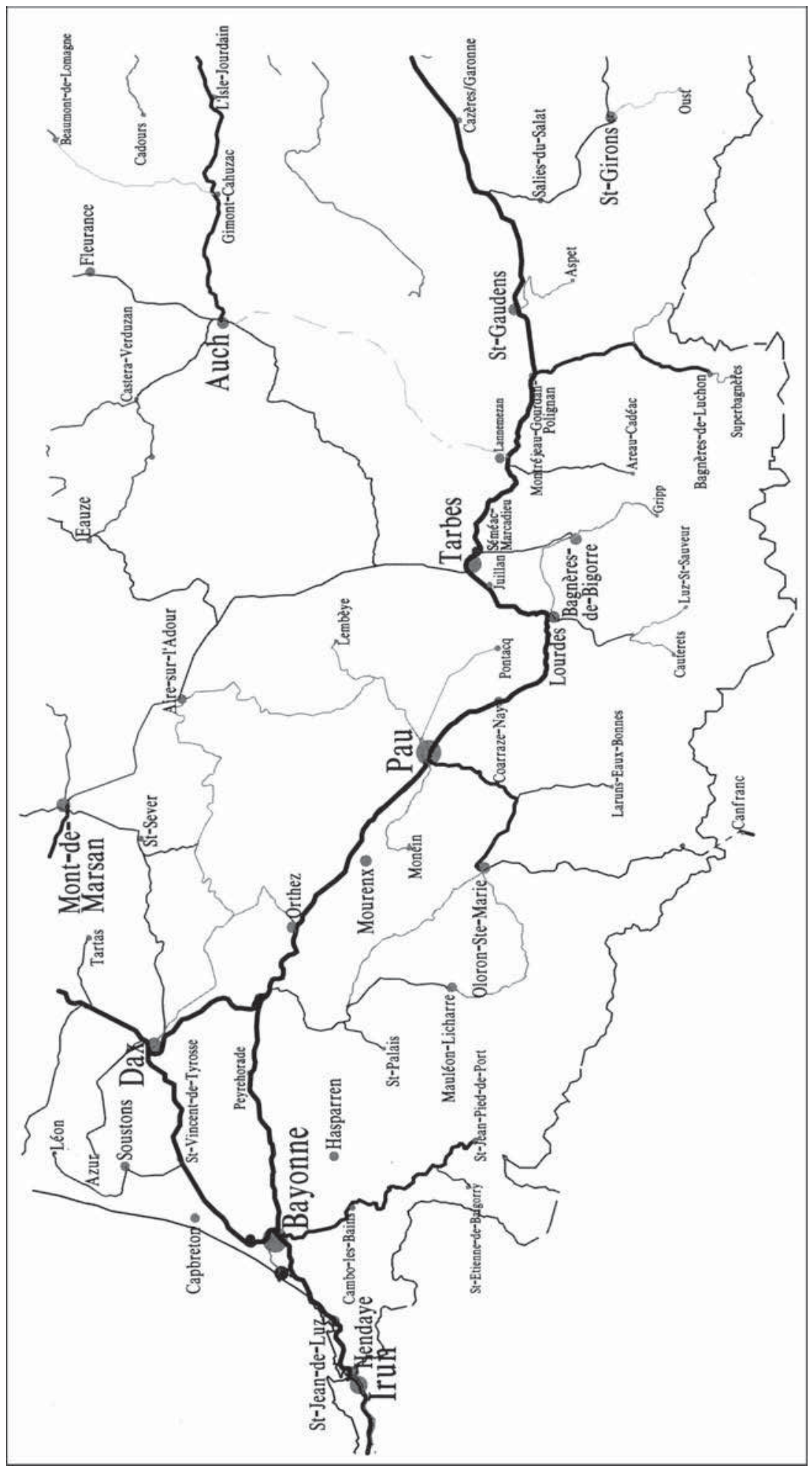

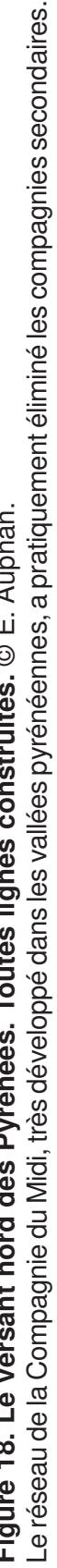


Les Landes (fig. 19) ont un réseau constitué de lignes plus ou moins parallèles aboutissant à l'axe du Midi, Bordeaux-Dax. Ces lignes viennent de l'Est, surtout de l'Ouest; parmi ces dernières deux seulement atteignent le littoral, à Biscarosse et Mimizan ; la vocation touristique n'est pas leur fait. Ces lignes étaient destinées au transport du bois, à prendre en charge aussi près que possible du lieu des coupes pour réduire un parcours par roulage très onéreux ; elles étaient généralement à voie normale et parcourues par des wagons du Midi; les problèmes de manutention aux gares de contact étaient éliminés ; les bifurcations pouvaient se localiser dans de petites stations sans équipement de levage, cela a permis de réduire le kilométrage à construire, ce qui n'aurait pas été le cas s'il avait fallu concentrer le trafic dans une ou deux gares de contact; nous ne sommes pas dans le modèle du transport par camion jusqu'aux récentes « gares-bois » du xxI siècle.

Le réseau landais a été conçu pour faire face aux besoins de transport d'une économie particulière, la production forestière. Il n'y a pas de réplique à cette situation ; les forêts vosgiennes ou jurassiennes n'ont pas entraîné la naissance d'un réseau spécialisé, même si les chemins de fer acheminaient le bois. Une comparaison peut être trouvée pour les réseaux dont les trafics reposaient sur une marchandise particulière et, éventuellement, sur le transport de la main-d'œuvre concernée par la production ou le traitement de ce produit : réseaux de desserte de régions minières ou encore de production betteravière.

\section{Modèles théoriques et réalité}

L'analyse cartographique de quelques cas et l'examen de beaucoup d'autres conduisent à définir deux types de réseaux théoriques.

Le cas idéal est représenté par un système de lignes radiales divergeant d'une préfecture localisée au centre du département ; ces lignes s'insinuent entre les axes du réseau d'intérêt général pour doter d'un équipement ferroviaire des zones qui en étaient dépourvues ; loin du centre, certaines lignes radiales étaient reliées entre elles. Ce schéma présentait toutes les caractéristiques permettant de le définir comme un réseau. Ce modèle suppose une volonté politique forte pour établir un programme, fixer des priorités, exécuter le projet ; il repose sur l'implication d'une compagnie prête à porter seule une grande partie du projet.

L'autre cas est celui d'un département doté d'une ou de plusieurs lignes conçues pour relier au plus court de modestes localités à la gare d'une grande compagnie ; une grande partie du département est privée de contact de proximité avec le chemin de fer. 


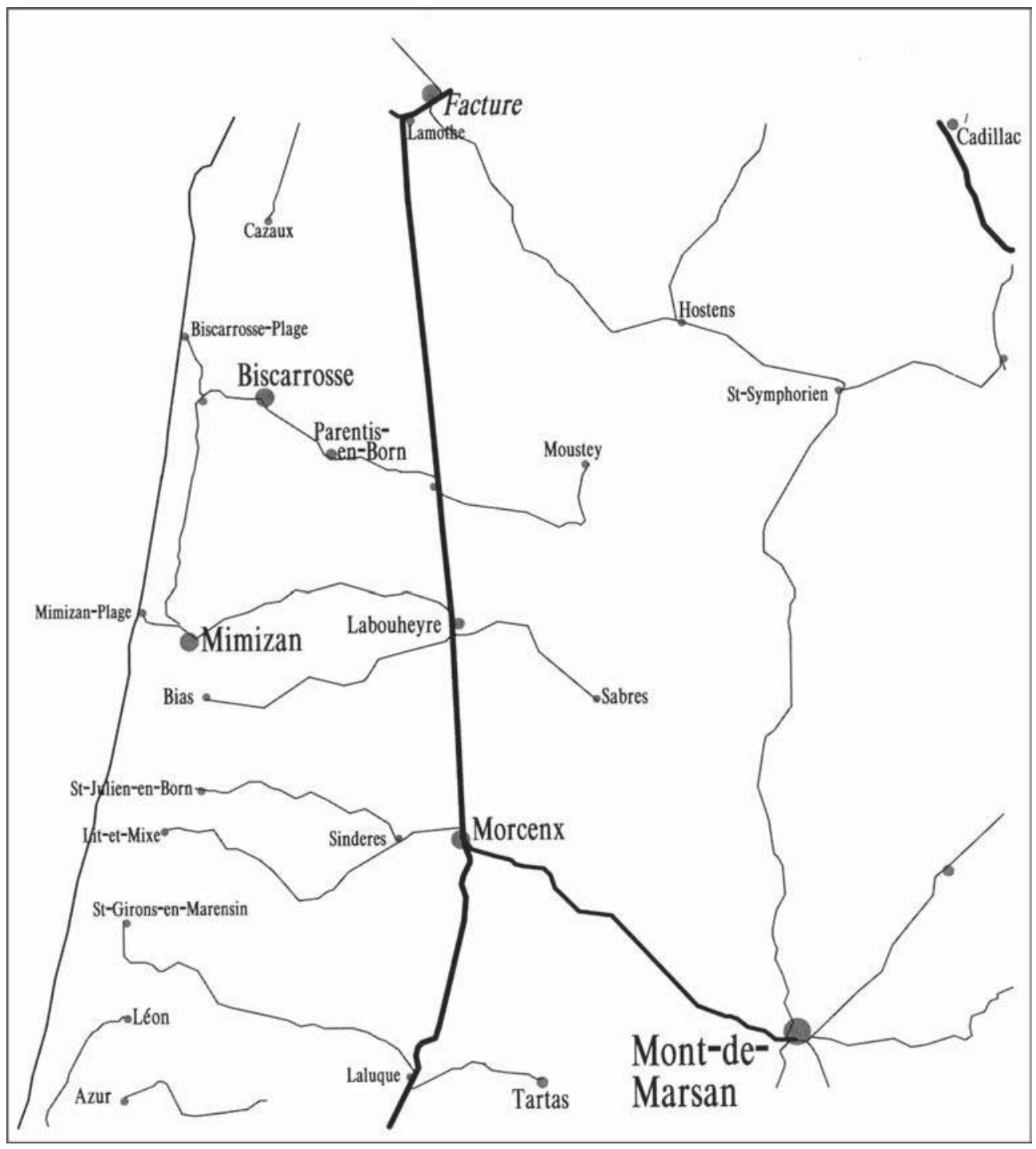

Figure 19. Le réseau ferroviaire des Landes. Toutes lignes construites. (C) E. Auphan Les Landes bénéficient d'un réseau formé de lignes isolées rejoignant l'artère maîtresse de la Compagnie du Midi, conçu pour la desserte des chantiers forestiers. 
La réalité sur le terrain est complexe ; divers facteurs perturbent la réalisation de ces modèles, l'un parfait, l'autre imparfait. Analyser les effets de ces facteurs sur la réalisation des modèles est possible, alors qu'établir une typologie dans laquelle classer chaque département semble une entreprise hasardeuse. Seules des monographies départementales permettent de définir l'originalité d'un réseau par rapport aux modèles, d'apprécier la qualité des services rendus à la population, d'expliquer par l'histoire les caractéristiques spatiales du réseau.

L'inachèvement, à un stade donné de l'exécution, d'un réseau radial programmé trouble le modèle prévu; un manque de moyens financiers, des différends politiques, un abandon, le maillage étant jugé suffisant, peuvent être à l'origine de la décision; les liaisons entre les radiales sont les victimes habituelles de ces décisions. Certains conseils généraux ayant une autre vision du rôle du réseau établissent un programme de construction qui ne doit rien au modèle radial ; le cas de la Gironde a été évoqué, reposant sur une ligne en arc de cercle unissant par l'ouest et le sud du département l'estuaire à la Garonne ${ }^{13}$. Dans le Cher (fig. 15), une seule ligne secondaire quitte Bourges, mais le département est desservi par un ensemble de lignes qui cumulent neuf points d'échange avec le PO : Bourges, Vierzon, La Guerche, SaintFlorent, Saint-Amand-Montrond, Veaugues, Henrichemont, Argent-sur-Sauldre, Châteaumeillant. L'objectif des lignes d'intérêt local complémentaires du grand réseau a été privilégié ; six lignes sont en correspondance parfois en plusieurs points : Paris à Toulouse, Nantes à Lyon, Bourges à Montluçon, à Cosne-sur-Loire et à Pithiviers, Montluçon à Châteauroux. Des facteurs aussi différents que l'obstacle constitué par une chaine de montagne, la position excentrée de la préfecture (Nièvre, Saône-et-Loire), la concurrence entre la préfecture et une autre ville (Pau et Bayonne, Châlons-sur-Marne et Reims, Quimper et Brest) n'empêchent pas l'existence d'un réseau étendu mais éloigné du modèle radial. Enfin, les Landes et le Nord nous ont montré comment la nature des activités économiques et la répartition de la population conduisaient à des réseaux étendus adaptés à ces situations.

Le second modèle, fréquemment réalisé, repose sur la liaison entre des localités et des gares d'un grand réseau. Le cas le plus simple est celui de courtes lignes isolées : plateau du Revard à Aix-les-Bains (9 km), Saint-Genix-d'Aoste à Saint-Béron PLM (17 km), La Rochette et Allevard-les-Bains à Pontcharra PLM $(8 \mathrm{~km})$ en Savoie, Billom à Vertaizon PLM (9 km) dans le Puy-de-Dôme ; le cas du Lot est exemplaire avec son unique ligne secondaire de $10 \mathrm{~km}$ reliant Saint-Céré à

13- Cf. ci-dessus, p. 71-75. 
Bretenoux-Biars PO. Les deux lignes convergent du Barcarès et de Thuir vers Perpignan ont en partie cette fonction, de même les localités le long de la ligne de $18 \mathrm{~km}$ unissant Riom PLM à Volvic PO. Rappelons aussi le cas du Cher.

Pour synthétiser, hors le Lot, neuf départements peuvent être identifiés à ce modèle : le kilométrage exploité se situe entre 39 et $75 \mathrm{~km}$; on compte en moyenne moins de quatre lignes par département, avec une moyenne de $16 \mathrm{~km}$ par ligne ; dans quatre départements, ces lignes n'ont aucun point commun, dans les autres deux partagent un terminus. On ne peut parler d'un réseau; dans la majorité des cas, chaque ligne est confiée à un exploitant différent.

\section{$>$ Le choix des conseils généraux}

Les conseils généraux ont eu des démarches différentes. Les uns avaient une vision de l'organisation de l'espace, traduite dans un réseau dont la construction a été inégalement achevée; aussi doit-on rattacher à ce modèle des départements dont les réseaux n'ont pas des dessins identiques. Les autres ont défini un nombre limité de liaisons indispensables, parfois après avoir élaboré des plans qu'ils n’ont pu réaliser. Sur quels éléments les élus se fondaient-ils pour guider leur choix ?

L'observation du réseau d'intérêt général en place et des extensions prévues était nécessaire ; cette connaissance était devenue indispensable après 1880 , lorsqu'il fallait tenir compte des projets et constructions de lignes inscrites au plan Freycinet ; ces lignes sont mises en service pendant les vingt années où se constitue l'essentiel du réseau des lignes secondaires; ces dernières avaient vocation à combler les vides laissés par les grands réseaux.

Le choix d'une politique départementale des chemins de fer a entrainé des débats dans lesquels certains élus et souvent le président du conseil général ont pris une place particulière, tentant de peser sur le choix des priorités. Des responsables des activités économiques, quelquefois des entrepreneurs de la construction ou de l'exploitation de voies ferrées émettaient des avis et suggéraient des solutions. Deux représentants de l'État, le préfet et l'ingénieur des Ponts et Chaussées en charge du département, ont exercé une grande influence par son pouvoir pour l'un, par sa compétence technique pour l'autre. Parmi eux, par conviction ou en fonction du réseau déjà en place, certains freinaient toute initiative pour limiter la concurrence aux grandes compagnies, d'autres se montraient réceptifs à la défense des intérêts locaux.

Le budget départemental étant mis à contribution, les élus devaient établir des plans compatibles avec leurs moyens dans le cadre du plan global de financement. Les départements où nous avons relevé la 
faiblesse du kilométrage exploité avec des lignes courtes et rares n'avaient peut-être pas les moyens de faire mieux ; ils se trouvaient, soit en zone agricole pauvre (Gers), soit en montagne ou avec de vastes étendues de hautes terres (Gard). Sans doute bien des départements auraient-ils adopté des plans plus ambitieux s'ils n'avaient pas été bridés par le poids des investissements.

Les prévisions de trafic auraient dû être un élément déterminant dans la définition de programmes de construction. Pour schématiser, la méthode employée par les grandes compagnies se fondait sur un nombre annuel de déplacements et sur un tonnage annuel à acheminer : l'évaluation se faisait pour les communes en fonction de leur distance à une station; le procédé ferait sourire les statisticiens du xxI ${ }^{\mathrm{e}}$ siècle. La construction des lignes secondaires se décidait sur la base d'affirmations péremptoires sur les potentiels du trafic à espérer, rarement sur des données objectives; les besoins étant importants, les compagnies n'ont pas souffert, au début, de cette situation. En 1911, une forte majorité d'entre elles présente un coefficient d'exploitation positif.

\section{. Réseaux de TV et de TVB}

\section{$>$ Les réseaux de $\mathrm{TV}$}

La liste des villes où des réseaux sont concédés et presque toujours exploités montre l'engouement pour cette technique ; elle inclut des localités de toutes tailles; 78 agglomérations sont concernées, des types très différents de lignes et de réseaux se sont constitués (tabl. 61).

Des lignes de 3 à $6 \mathrm{~km}$ unissent des localités à la gare lointaine qui porte leur nom (Cassel, Marquise...), d'autres, une banlieue à la ville voisine (Denain à Lourches, Saint-Pol-sur-Mer à Dunkerque).

Une douzaine de lignes dont beaucoup dépassent $10 \mathrm{~km}$ ont une vocation touristique caractérisée, soit en montagne (ClermontFerrand au sommet du Puy-de-Dôme, Gérardmer à La Schlucht), soit sur le littoral (Saint-Georges-de-Didonne à La Grande-Côte...), soit pour relier une station thermale à une gare (Aubenas à Vals-les-Bains, Moutiers à Brides-les-Bains). Certaines stations thermales ou climatiques (Aix-les-Bains, Les Eaux-Bonnes, Saint-Galmier, Trouville...) se sont dotées de tramways pour offrir à leur clientèle le moyen de transport dont elle disposait dans sa ville de domicile.

Le TV a été regardé comme un lien indispensable entre les gares et le cœur de la ville, particulièrement si une forte dénivellation existe entre les deux (Angoulême, Besançon, Poitiers...) : ce lien est le point de départ de multiples réseaux. L'extension des villes en surface avec une population croissante nécessitait un mode de transport permettant de 
faire face à l'allongement des déplacements. Existe-t-il un seuil de population à partir duquel ce besoin s'est imposé ? La réponse semble différente pour les préfectures et pour les autres villes. En 1901, en France, les unités urbaines de plus de 50000 habitants ne sont que 37 ; 5 seulement dépassent 200000 habitants.

Tableau 61. Liste alphabétique des villes bénéficiant d'une ou plusieurs concessions de lignes ou de réseaux de tramways (a)

\begin{tabular}{|c|c|c|}
\hline Aix-les-Bains & Grenoble & Reims \\
\hline Amiens & Le Havre & Rennes \\
\hline Angers & Isle-sur-Sorgue & Roanne \\
\hline Angoulême & Lille & Rochelle (La) \\
\hline Avignon & Limoges & Rodez \\
\hline Bayonne & Livry & Rouen \\
\hline Belfort & Lorient & Roubaix \\
\hline Besancon & Lourches & Saumur \\
\hline Béziers & Lourdes & Sedan \\
\hline Blois & Lyon & Seyne (La) \\
\hline Bordeaux & Le Mans & Saint-Galmier \\
\hline Boulogne & Marquise & Saint-Pol-Sur-Mer \\
\hline Bourges & Marseille & Saint-Quentin \\
\hline Caen & Montargis & Saint-Etienne \\
\hline Calais & Montpellier & Toulon \\
\hline Cambrai & Nancy & Toulouse \\
\hline Cassel & Nantes & Tourcoing \\
\hline Cette & Nevers & Tours \\
\hline Châlons-sur-Marne & Nice & Trouville \\
\hline Cherbourg & Nimes & Troyes \\
\hline Clermont-Ferrand & Orléans & Valenciennes \\
\hline Cusset & Paris & Vals-les-Bains \\
\hline Dijon & $\underline{\mathrm{Pau}}$ & Versailles \\
\hline Dunkerque & Perpignan & Vaucluse (27) \\
\hline Les Eaux Bonnes & Poitiers & \\
\hline Elbeuf & Pont-de-Vaux & \\
\hline Épinal & Puy (Le) & \\
\hline
\end{tabular}

a) Les noms soulignés sont ceux de préfectures. 
Pour les préfectures, le seuil se situe entre 30000 et 35000 habitants ; au-dessus, toutes disposent de tramways ; au-dessous, les préfectures n'ont pas de réseau (Moulins, Laval, Chartres, Albi, Châteauroux...) avec des populations comprises entre 21000 et 33000 habitants; a fortiori il en va de même pour les plus petites (Auch, Digne, Guéret, Lons-le-Saunier...). Le cas de Tours est exemplaire. La ville a 50000 habitants lorsqu'elle se dote d'une première ligne en 1877. Le mode de traction est modernisé, passant à la vapeur en 1895 et à l'électricité dès 1899 ; dès lors le réseau se développe rapidement, parallèlement à la croissance de la population, qui atteint 70000 habitants tandis que le réseau compte $20 \mathrm{~km}$ en 1911.

Pour les villes industrielles et portuaires, le volume de population intervient, mais la composition socio-professionnelle a sa place en assurant une clientèle potentielle d'ouvriers et d'employés, moins représentée dans les préfectures. Les villes de plus de 100000 habitants sont évidemment équipées (Roubaix, Le Havre, Toulon) mais aussi Tourcoing (80 000 habitants) et, plus caractéristiques, des villes industrielles comptant de 15000 à 25000 habitants (Cambrai, Elbeuf, Sedan...) et de multiples ports (militaires, de pêche ou de commerce : Cherbourg, Boulogne-sur-Mer, Lorient, Bayonne, Calais, Cette...).

Les principales villes bénéficient des plus longs réseaux, mais il n'y a pas une proportion parfaite entre kilométrage et volume de population : il faut tenir compte de la superficie des villes et de l'inégale pénétration des tramways dans les communes voisines de banlieue (tabl. 62). Dans la majeure partie des cas ces réseaux ne sont pas encore achevés, quelques kilomètres restent à construire. Dans beaucoup de villes, le réseau est confié à un seul exploitant (Marseille, Nantes, Nice, Reims...) qui privilégie le réseau intra-urbain et essaye d'assurer une bonne irrigation de l'espace ; dans d'autres, deux (Lyon, Saint-Étienne, Nancy), voire cinq concessionnaires se partagent la desserte. Les parcours communs ou concurrents sont nombreux, les lignes se prolongeant plus fréquemment après la circulation en ville vers des banlieues jusqu'à 10 ou $15 \mathrm{~km}$ (Caluire à Lyon).

Le cas de Paris et de la Seine mérite intérêt. Outre deux compagnies de CFIL exploitant des réseaux souterrains, 14 concessions dont trois sans résultat ont été accordées pour la réalisation du réseau de surface. La Compagnie de chemin de fer sur route de Paris à Arpajon relève du régime de TVM ; elle achemine vers les Halles par le boulevard Saint-Michel les produits maraîchers; elle est seule sur ses $10 \mathrm{~km}$ dans Paris et la Seine (26 km en Seine-et-Oise) à faire circuler des marchandises dans les rues de la capitale. Trois compagnies accaparent les 
deux tiers des $517 \mathrm{~km}$ tracés à travers la ville et sa banlieue immédiate : la Compagnie générale des omnibus de Paris (120 km, 23,2\%), la Compagnie des tramways de Paris et du département de la Seine $(137 \mathrm{~km}, 26,5 \%)$, la Compagnie des tramways de l'est parisien $(85 \mathrm{~km}$, $16,4 \%$ ). Les six autres exploitent entre 6 et $64 \mathrm{~km}$ (annexe 1).

Tableau 62. Les réseaux de tramways voyageurs dans les principales villes

\begin{tabular}{|l|c|c|c|c|}
\hline \multicolumn{1}{|c|}{ Ville } & Population & $\begin{array}{c}\text { Concédés } \\
(\mathbf{k m})\end{array}$ & $\begin{array}{c}\text { Exploités } \\
(\mathbf{k m}) \mathbf{1 9 1 1}\end{array}$ & $\mathbf{1 9 2 7}$ \\
\hline Marseille & 550000 & 185 & 164 & 168 \\
\hline Lyon & 523000 & 169 & 165 & 202 \\
\hline Bordeaux & 261000 & 130 & 124 & 136 \\
\hline Lille & 217000 & 104 & 103 & 102 \\
\hline Nantes & 170000 & 59 & 39 & 42 \\
\hline Toulouse & 150000 & 62 & 55 & 89 \\
\hline Saint-Etienne & 149000 & 80 & 75 & 84 \\
\hline Nice & 142000 & 38 & 32 & 30 \\
\hline Le Havre & 136000 & 40 & 39 & 42 \\
\hline Roubaix & 122000 & 31 & 29 & 45 \\
\hline Nancy & 119000 & 59 & 54 & 66 \\
\hline Reims & 115000 & 22 & 22 & 20 \\
\hline Toulon & 104000 & 27 & 27 & 31 \\
\hline
\end{tabular}

Au terme de ces analyses, on peut considérer que les réseaux de quatre villes, Marseille, Lyon, Bordeaux et Lille disposent d'un kilométrage voisin de celui en service à Paris et dans la Seine. Ensemble ces cinq agglomérations monopolisent environ la moitié du total national des lignes de TV. Le tramway trouve en ville son terrain d'élection.

\section{$>$ Les réseaux de TVB}

La gestion d'un TVB a des exigences supérieures à celles d'un TV $:$ l'acheminement des bagages et messageries suppose l'émission de bulletins d'enregistrement ou d'expédition, des lieux d'entreposition, des manutentions, des contacts avec d'autres réseaux, donc des personnels. Il est surprenant de voir Blois, 25000 habitants, la plus petite préfecture à se doter d'un tramway, opter pour le TVB pour desservir les $7 \mathrm{~km}$ de son réseau. Il est vrai que Rodez, avec 16000 habitants, avait choisi un TVM pour relier sur $2 \mathrm{~km}$ sa gare au palais de Justice!

Le choix de Nice se comprend aisément. La concession accordée à la Compagnie des tramways de Nice et du littoral portait sur un réseau urbain de $30 \mathrm{~km}$, sur la liaison entre Nice et Cimiez $(4 \mathrm{~km})$ où se 
multipliaient les hôtels les plus luxueux, sur la desserte de Saint-JeanCap-Ferrat (2 km) et enfin sur la ligne de Cagnes à Menton (45 km), qui participait au service urbain dans Nice et se terminait par un court réseau dans Menton, soit en tout $81 \mathrm{~km}$. Ce réseau, en hiver, bénéficiait d'une clientèle importante, dont les bagages pesants et volumineux devaient être acheminés à proximité de son lieu de séjour. À Saint-Étienne, les lignes vers Firminy et Rive-de-Gier (64 km) participaient à la desserte de la ville. Dans ces deux cas, on comprend l'absence ou la faiblesse des réseaux de TV face aux lignes de TVB.

Le terminus marseillais de la ligne pour Aix-en-Provence a d'abord été fixé à Saint-Antoine où les TV de la Compagnie générale française des tramways, concessionnaire du réseau urbain, conduisaient les voyageurs. Le concessionnaire de la ligne d'Aix voulait s'assurer une pénétration au centre de Marseille ; il lui a fallu des années pour vaincre l'opposition de sa rivale citadine et accepter un terminus à la place du Change et non au Cours Belsunce, beaucoup mieux situé ${ }^{14}$. Ce type de conflit au sein des villes est fréquent, aucun ne voulant céder la moindre part de trafic. Des arguments techniques, souvent spécieux, étaient mis en avant pour justifier des refus d'une utilisation commune des voies (garage des rames, croisements, intensité du trafic...).

Beaucoup de lignes reliant une gare à une localité proche sont régies par ce statut (Livry à Villiers-le-Bel). De même, comme sur la Côte-d'Azur, des liaisons de TVB permettent l'acheminement des bagages entre Saint-Malo-ouest et Paramé, Étaples-nord et Paris-plage ou Moutiers PLM et Brides-les-Bains...

Les compagnies de TV urbains sont souvent concessionnaires de lignes de TVB desservant les zones suburbaines, ou même reliant la ville à une localité proche (Bordeaux à Léognan, Nancy à Dombasle, Tours à Vouvray, Versailles à Saint-Cyr-l'École...) ; les statistiques font apparaître ces compagnies sous les rubriques consacrées à chaque statut, tantôt avec le kilométrage des lignes définies, tantôt avec une ventilation des kilomètres exploités sous chaque statut (Angers, Cannes, Grenoble, Rennes...). Deux concessions de TVB viennent compléter le réseau parisien : $90 \mathrm{~km}$ pour la Compagnie générale des tramways, $184 \mathrm{~km}$ pour la Compagnie des tramways de l'est parisien, bénéficiant d'une incursion en Seine-et-Oise.

Le réseau des TVB est fort de $929 \mathrm{~km}$ répartis entre près de 40 lignes.

14- Les Tramways de Marseille ont cent ans. La ligne d'Aix-en-Provence, ve partie, s. d., p. $549-561$. 
En dix ans, les terres cultivées ont progressé au détriment des friches ; la commercialisation des produits agricoles a réduit la part de l'auto-consommation ; la mécanisation a touché davantage d'exploitations agricoles ; les foires et les marchés, les activités touristiques se sont fixés dans les communes directement desservies par le rail, notamment par les réseaux secondaires. En 1911, ces réseaux sont étendus, les nouvelles concessions de CFIL ou de TVM sont rares : mais les progrès du monde rural et des zones de loisirs liés au chemin de fer conduisent les hommes politiques à vouloir que les concessions aboutissent à la mise en service de nouvelles lignes. La desserte nécessaire de nouveaux quartiers conduisait les conseillers municipaux à de mêmes conclusions pour les TV. 


\title{
Annexe 4
}

\section{Demande de concession d'une ligne de tramways à Paris}

\author{
D IEPATHMEN'T I)E LA SEINE
}

VILII DE PARIS

\section{CIIENIINS DE FER SLIBURBIINS}

A VOIE ÉTROITE

\section{EXPOSÉ DU PROJET}

$1^{\circ}$ Entre les Chemins de fer à la voie de $1 \mathrm{~m}$. 50, à grande vitesse, aux stations éloignées, coûteux d'établissement et d'exploitation, et exigeant, par suite, de gros produits, - et les omnibus qui suivent la route comnune, marchent lentement et s'arrètent à chaque instant, il y a place pour un intermédiaire important; - c'est le chemin de fer à voie étroite $(1 \mathrm{~m} .00)$, établi à peu de frais sur l'accotement des routes, - passant, comme les omnibus, au milieu des populations, circulant sur les routes, avec une vitesse plus grande, s'arrêtant tous les 1,500 mètres ou tous les 2,000 mètres, exploité sans gares, avec un personnel réduit et par conséquent à peu de frais, et n'exigeant, en définitive, que de faibles revenus; 


\section{$-2-$}

2" Le mouvement croissant qui se produit aux gares de banlieue prouve que les tendances it l'imigration augmentent sans cesse. I a vie est moins chìre hors Paris, et le prix de l'abonnement au chemin de fer n'absorbe pas la différence. La facilité des communications développe les goùts de villigiature, et, à côté des personnes aux revenus modestes, qui vivent toute l'année dans la banlieue, se trouvent les personnes plus aisées qui, durant la belle saison, vitmnent à leurs affaires à Paris chaque matin et rentrent chaque soir ì la campagne.

On doit également désirer, dans l'intérèt bien entendu de la population ouvrière proprement dite, des trains partant de la banlieue d'assez bonne heure, pour que les ouvriers puissent quitter les faubourgs, vivre à meilleur compte et au meilleur air dans la baulieue, et être transportés au centre de Paris à l'heure matinale à laquelle commencent leurs travaux. Il y aurait pour eux écononic de temps et d'argent, profit pour leur bourse, pour leur santé et celle de leur famille. Des trains d'ouvriers ont été créés dans les pays industriels et miniers, aux environs de Mulhouse, sur le chemin de Graissessac. Il u'en existe pas à Paris.

L.es petits employés seuls ont pu profiter des trains de banlieue établis plus spécialement sur les lignes de l'Ouest, du Nord, de Vincennes. Et, à côté des communes anciennes dont la population augmentait dans de fortes proportions, il s'est formé des communes nouvelles comme Levallois-Perret, la Garenne, le Vésinet, etc. Cette tendance paraît ètre un des besoins de l'époque.

Par conséquent, tous les moyens de transport qui pourront seconder les rlésirs si manifestes et si légitimes des diverses classes de la population parisienne, seront évidemment bien accueillis par elle, et profiteront aux projets de décentralisation qui préoccupent l'esprit public en ce moment.

Ces considérations ont inspiré le présent projet, que ses auteurs soumettent avec confiance à l'examen de l'Administration et du Conseil général du département de la Seine.

Il s'agit :

$1^{\circ}$ D'établir des chemins de fer (système américain) sur les grandes voies existantes; 
$2^{\circ}$ De remorquer les trains par des locomotives.

I'avis des hommes les plus compétents, l'exemple de ce qui se passe dans les villes les plus populeuses de l'étranger (en Angleterre et en Améri(ue), - et en France, à Paris et dans plusieurs autres grandes villes, dans des conditions tout a fait semblables, donnent l'assurance que la marche de ces trains peut avoir lieu sans danger pour la circulation publique.

Aux mois de juillet, aout, septembre et octobre 1861, la Société des Ingénieurs civils a examiné et discuté longuement les conclusions d'une étude qui lui était présentée par MM. Molinos et Prosnier, relative à l'utilisation des routes pour l'établissement de chemins de fer économiques.

Il a éti rappelé par M. Forquenot que !e chemin de ler de Nantes à Saint-Nazaire traversait Nantes le long des quais, sur une longueur de plusieurs kilomètres, les machines circulant avec une vitesse réglée par l'Administration supéricure, à 16 kilomètres par heure; M. Goschler a rapporté qu'à Bruxelles les gares du Nord et du Midi étaient relićes entre elles par une voie non close établie le long du canal; - qu'à Berlin, une voie reliant les chemins de fer venant de Cologne d'une part et de Stettin de l'autre, était établie sur une promenade analogue à nos Champs-Elysées; - qu'à Dresde une ligne réunissait les chemins de fer venant de Leipzig duue part et de Vienne de l'autre.

Nous ne parlerons pas des ramways, aujourd'hui bien connus, dont le nombre augmente sans cesse et qui ont pris aux Etats-Unis un développement considérable. Mais nous devons signaler d'une manière spéciale les Dummy-Cars ou wagons à vapeur sur rails, employés à New-York sur quatre lignes urbaines, d'une longueur totale de 27 milles 86 (45 kilomètres environ), et qui transportent annuellement plus de 10 millions de voyageurs.

Dans tous les ports, aujourd'hui, à Marseille, a Cette, à Bordeaux, à Rouen, au Havre, etc., des trains circulent et, gràce à une sage réglementation, le commerce profite de l'écononie que donnent les voies ferrées et la traction à vapeur opérée sur celles-ci, sans que les autres transports qui ont lieu parallèlement en soient nullement gênés: 


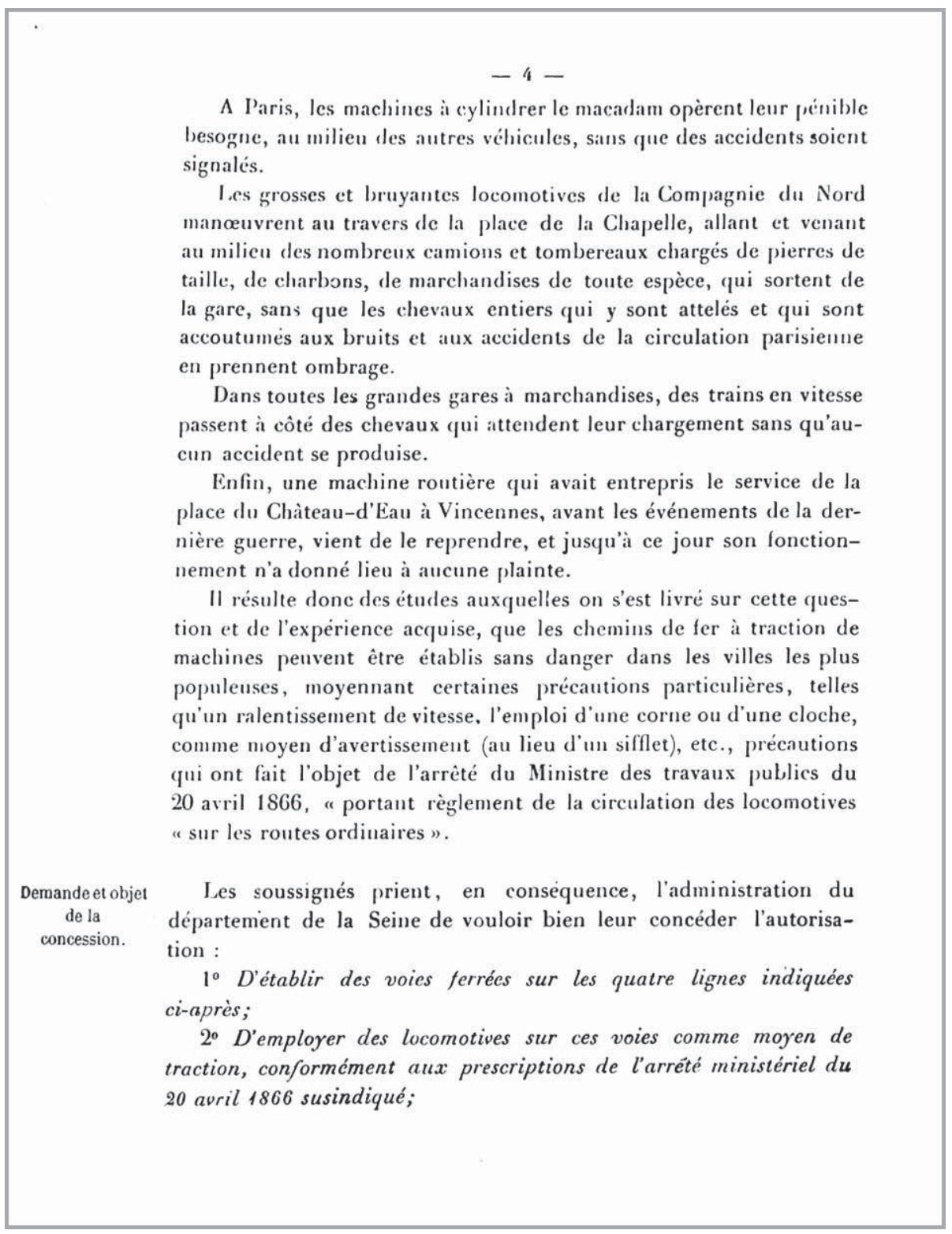


$3^{\circ}$ Iit d'exploiter lestits cluomins de fer pendant une durée de cinquante annécs.

Les quatre lignes dont l'établissement est projeté sont les suivantes :

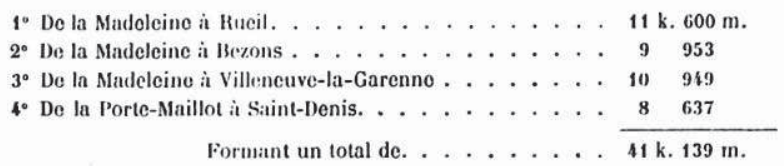

Les itinéraires suivis par ces lignes sont les suivants:

\section{I" LIGNE. - DE L'ÉgLISE DE LA MADELEINE A RUEIL LONGUEUR......... 11 k. $600 \mathrm{~m}$.}

La voie partant de l'église de la Madeleine remonte le boulevard Malesherbes jusqu'à l'église Saint-Augustin; elle prend alors le boulevard Haussmann, contourne l'are de triomphe de l'Etoile, puis redescend l'avenue de la Grande-Armée jusqu'au pont de Neuilly. Elle traverse la Seine sur cet ouvrage, puis gravit la montée du rondpoint de Courbevoie.

La ligne continue a suivre l'accotement de la route nationale n' 13 de Cherbourg, rencontrant Nanterre et Rueil, où clle s'arrète à l'angle de la rue qui conduit au centre de la ville.

La longueur de cette ligne serait de 11 k. 600 m.

Les stations seraient les suivantes :

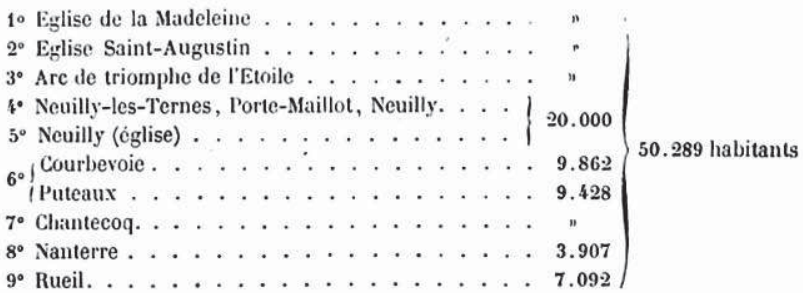

La distance moyenne entre les stations est de 1,450 mètres. 


\section{$-6-$}

Il y aurait, en outre, deux haltes : l'une au rond-point de Courbevoie, l'autre au chemin qui conduit au Mont-Valérien.

La moyenne de lit population des cinq communes traversées est de 10,058 habitants.

\section{LIGNE. - DE L'ÉgLISE DE LA MAdeleine A Bezons}

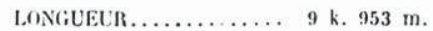

Comme la précédente, cette ligne part de l'église de la Madeleine, où un bureau commun servira de station de départ. Elle remonte le boulevard Malesherbes jusqu'i la place de ce nom, prend alors le boulevard de Neuilly jusqu'aux fortifications, et, à la suite, le boulevard Bineau jusqu'ì la Seine, qu'elle traverse sur les deux ponts de l'ile de la Grande-Jatte. Elle suit alors la nouvelle route en construction (prolongement du boulevard Bineau) et, passant à droite du village de Courbevoie, elle arrive au rond-point du village de la Garenne. De lik, elle se dirige vers la route $\mathrm{n}^{\circ} 192$, de Pontoise, et la rejoint un peu en amont du pont du chemin de fer, it Charlebourg. Elle suit l'un des accotements de cette route jusqu'a Bezons, point terminus.

La longueur de cette ligne serait de 9 k. $953 \mathrm{~m}$.

Les stations seraient les suivantes:

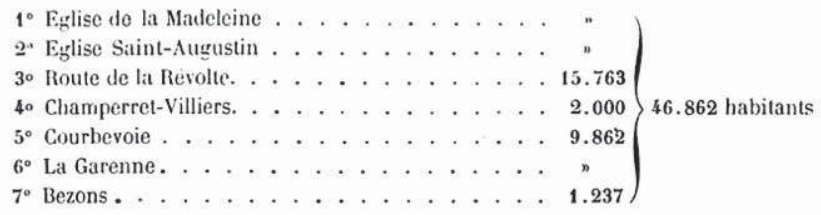

Distance moyenne entre les stations : $1 \mathrm{k} .660 \mathrm{~m}$.

Population moyenne des quatre stations pour lesquelles des chiffres ont pu ètre recueillis : 11,715 habitants. 


\section{3* Ligne. - DE L'Église de la madeleine a villeneuVe-la-garenne}

I.ONiII EUH......... 10 k. $949 \mathrm{~m}$.

Cette ligne part de l'église de la Madeleine, et suit le tracé de la seconde ligne jusqu'i la place Malesherbes. A partir de là, elle continue à suivre le mème boulevard jusqu'ì la place Wagran, prend le boulevard de ce nom, franchit la porte d'Asnières et prend alors la route de la Révolte jusqu'au boulevard Saint-Vincent-de-Paule, qu'elle suit dans toute la traversée du village de Clichy-la-Garenne jusqu'à la Seine.

Elle franchit le fleuve sur les trois ponts de l'ile Robinson et de l'île Vaillard, et arrive à la droite du village d'Asnières. Elle prend alors la route $n^{\circ} 7$ de Genneviliers, traverse cette commune, puis, tournant it droite, vient prendre le chemin de grande communication $\mathrm{n}^{\circ} 6$, de Saint-Denis à Nanterre.

La longueur de cette ligne serait de 10 k. $949 \mathrm{~m}$.

Les stations seraient les suivantes:

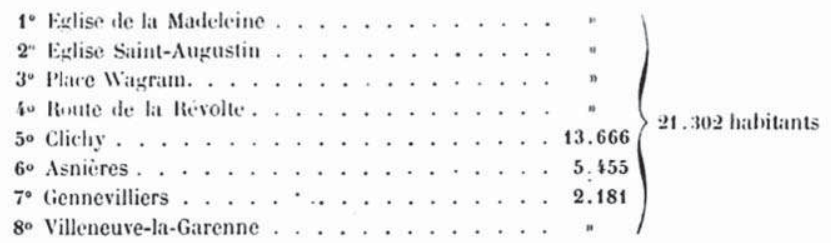

La distance moyenne entre les stations est de $1 \mathrm{k} .564 \mathrm{~m}$.

La population moyenue des stations pour lesquelles des chiffres figurent ci-dessus, est de 7,100 habitants.

\section{LIGNE. - DE NEUILLY-LES-TERNES A SAINT-DENIS} LONGUEUR.......... 8 k. $637 \mathrm{~m}$.

Comme complément des trois lignes qui précèdent se présente la ligne de Saint-Denis à Neuilly, qui les coupe toutes trois, et suit sur une longueur totale de $8 \mathrm{k} .637 \mathrm{~m}$. la route de la Révolte, ou route départementale $n^{\circ} 11$, de Saint-Denis à Versailles. 


$$
-8-
$$

I.es stations seraient les suivantes:

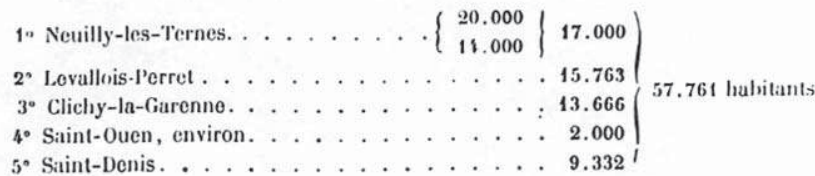

La distance moyenne entre les stations est de 2 k. $150 \mathrm{~m}$.

La population moyenne par station scrait de 11,552 habitants.

Il y aurait, en outre, trois haltes: au rond-point des Ternes; it là rencontre de la route $n^{\circ} 33$, et avant l'entrée de Saint-Denis, au canal.

Bases projetées d'exécution.
10 Voie. - La voie, de $1 \mathrm{~m}$. de largeur, sera établie en rails de deux espèces, du poids de 17 kilog. environ:

$1^{\circ}$ Rails ì ornière, du système américain, sur les partics de la chaussée des routes parcourues par les autres véhicules;

20 Rails à table saillante, du système Vignole, sur les accotements parcourus seulement par les piétons.

Dans les deux cas, la surface du rail sera affleurée au niveau du sol.

$2^{\circ}$ Matériel remorqueur et roulant. - La faible largeur de la voie entraine l'adoption d'un matériel roulant à essieux rapprochés, capables de tourner dans des courbes de faible rayon, et de se plier, par suite, aux exigences du tracé des routes existantes.

Dans l'intérieur de Paris, la distance de la voie au trotteir sera suffisante pour permettre le stationnement des voitures le long de ces trottoirs.

Les voitures à voyageurs seront à quatre roues et à deux étages. Elles contiendront de 36 à 45 places, et pèseront environ 5,000 kilog. à vide, soit 7,500 à 8,200 en charge.

Les machines-tender seront de deux types :

$1^{\circ}$ De 11 tonnes pour le chemin de Rueil;

$2^{\circ}$ De 8 tonnes pour les trois autres qui présentent des pentes moins rapides, ce qui correspond à 5 tonnes $1 / 2$ par essieu pour les premières, et à 4 tonnes par essieu pour les secondes. 


\section{$-9$}

Les trains pourront n'ivoir en semaine que 3 voitures, soit $24 \mathrm{~m}$. de longueur environ, machine comprise. Les dimanches et jours de fètes, leur longueur pourra ètre plus grande, ce qui sera saus inconvénient puisque les tombereaux, camions et autres véhicules servant au transport des fardeaux, et dont l'allure est plus particulièrement lente et difficile, sont beaucoup plus rares.

30 Stations, Dépóts, Atclier. - Le service que les quatre lignes proposées devront accomplir étant surtout un service de voyageurs, les stations se réduiront à un bureau d'attente et de distribution de billets, - soit une maisonnette en charpente placée sur le bord de la voie, soit une boutique disposée comme les bureaux de correspondance de la Compagnie des omnibus.

On espère que la ville et les communes traversées voudront bien consentir à l'ćtablissement gratuit de ces stations, dont les dimensions et l'installation seront d'ailleurs concertées avec la Direction des voies et promenades, et avec le Service des ponts-et-chaussées.

Indépendamment de la remise qui sera établie à l'extrémité de chaque ligne (hors Paris), un dépòt général avec atelier-annexe pour les réparations, sera créé aux abords du chemin de la Révolte. C'est de là que partiront les trains tout composés, chacque inatin, pour commencer leur service ; c'est là qu'ils rentreront, le soir, après la journée faite.

Exploitation. Les habitudes du public parisien, et, plus spécialement, des voyageurs de la banlieue, qui font chaque jour le voyage de Paris, rendront certainement très-facile l'exploitation des quatre lignes proposées. La faible longueur des lignes, l'établissement de croisements en nombre suffisant assureront complétement la marche des trains sur la voie unique.

Le projet comporte un départ de chaque extrémité - toutes les heures, le matin et le soir, - et toutes les deux heures seulement dans le milieu de la journée, si la circulation des voyageurs y est moins active.

On propose d'admettre une vitesse de 16 kilom. à l'heure dans Paris. Dans le but d'éviter tout inconvénient pour la circulation pu- 
blique, cette vitesse serait neutralisce facilement it l'aide de freins d'une puissance sulfisante, placés sur la machine et sur la dernière voiture, de manière ì permettre un arrêt aussi prompt que possible, chaque fois qu'un encombrement le rendrait nécessaire.

D'après les prévisions indiquées précédemment, les voitures contiendraient de 36 a 45 places chacune, d'où il suit qu'avec 16 trains de 3 voitures au minimum par jour, dans chaque sens, il y aurait à la disposition du public un total variable de 3,456 à 4,320 places sur chaque ligne, - soit pour les quatre lignes de 13,824 à 17,280 places par jour.

Les voitures auraient des places de deux classes au moins, une caisse ou compartiment à bagages et messageries, et des compartiments spécialement affectés aux fumeurs.

Les prix ì percevoir pour le transport des voyageurs, bagages et messageries, seraient ceux des grandes lignes.

Si les chemins projetés ne permettent de marcher qu'a une vitesse moindre que celle des voies ferrées existantes, ils ont comme compensation l'avantage de prendre les voyageurs au centre même des pays qu'ils habitent et de les déposer au centre de Paris, an point de départ de la ligne-maîtresse des omnibus, qui va de la Madeleine à la Bastille et correspond avec tous les autres quartiers.

Les soussignés, en échange du droit qui leur serait concédé par l'Administration, prennent à leur charge l'entretien ordinaire, pendant toute la durée de la concession, de la partie de la voie publique comprise entre les rails et de deux zònes latérales de $0^{\mathrm{m}}, 50^{\mathrm{c}}$ de largeur chacune, à droite et à gauche des rails.

Ils s'engagent envers M. le Préfet de la Seine à remplir, dans le délai maximum de deux mois, à partir de la date de la concession définitive, les conditions ci-après :

$1^{\circ}$ Fournir le cautionnement qui pourrait être exigé.

$2^{\circ}$ Constituer une société qui justifiera des ressources nécessaires à l'exécution des lignes projetées et qui sera chargée de les exploiter. 


\section{$-11-$}

Ils prennent en outre, l'engagement de livrer lesdites lignes ì l'exploitation dans le délai de deux années, à dater de la concession définitive qui leur serait consentie;

De soumettre les études et projets d'exécution à l'approbation des Autorités compétentes;

Et, à la fin de la concession, de laisser au département de la Seine les voies établies et les constructions, dans l'état où elles se trouveront alors.

A Paris, le 22 octobre 1871.

\section{Les Demandeurs en concession,}

Signé : L. TENRÉ, Banquier, 13, rue Laffille;

CII. TARAULT, Proprielaire, 115, boulerard llaussmann;

F. DUBUS, Secrélaire géeéral de Chemins de fer d'intérél local, 11, boulerard de la Madeleine. 